\title{
Communication and social interaction in the cannabinoid-type 1 receptor null mouse: Implications for autism spectrum disorder
}

\author{
William Fyke ${ }^{1,2}$ (1) | Marika Premoli ${ }^{3}$ | Victor Echeverry Alzate ${ }^{4,5}$ | \\ José A. López-Moreno $^{4}$ | Valerie Lemaire-Mayo ${ }^{1}$ | Wim E. Crusio ${ }^{1}$ | \\ Giovanni Marsicano $^{6}$ | Markus Wöhr ${ }^{7,8,9,10}$ | Susanna Pietropaolo ${ }^{1}$ (i) \\ ${ }^{1}$ University of Bordeaux, CNRS, EPHE, INCIA, UMR 5287, Bordeaux, France \\ ${ }^{2}$ Graduate Program in Neural and Behavioral Science, SUNY Downstate Medical Center, Brooklyn, New York, USA \\ ${ }^{3}$ Department of Molecular and Translational Medicine, University of Brescia, Brescia, Italy \\ ${ }^{4}$ Department of Psychobiology and Methodology on Behavioral Sciences, Faculty of Psychology, Madrid Complutense University, Spain \\ ${ }^{5}$ Unidad Gestión Clínica de Salud Mental, Instituto de Investigación Biomédica de Málaga (IBIMA), Hospital Regional Universitario de Málaga, Malaga University, Spain \\ ${ }^{6}$ University of Bordeaux, INSERM, U862 NeuroCentre Magendie, Group Endocannabinoids and Neuroadaptation, Bordeaux, France \\ ${ }^{7}$ KU Leuven, Faculty of Psychology and Educational Sciences, Research Unit Brain and Cognition, Laboratory of Biological Psychology, Social and Affective \\ Neuroscience Research Group, Leuven, Belgium \\ ${ }^{8} \mathrm{KU}$ Leuven, Leuven Brain Institute, Leuven, Belgium \\ ${ }^{9}$ Faculty of Psychology, Experimental and Biological Psychology, Behavioral Neuroscience, Philipps-University of Marburg, Marburg, Germany \\ ${ }^{10}$ Center for Mind, Brain and Behavior, Philipps-University of Marburg, Marburg, Germany
}

Correspondence

Susanna Pietropaolo, Bordeaux University and CNRS, INCIA, UMR 5287, Bat B2, Allée Geoffroy St. Hilaire, CS 50023, 33615 Pessac cedex, France.

Email: susanna.pietropaolo@u-bordeaux.fr

\section{Funding information}

Brescia University College; Centre National de la Recherche Scientifique; Consorzio Interuniversitario Biotecnologie; Fondo de Investigación Sanitaria, Grant/Award Number: RD16/0017/0008; Instituto de Salud Carlos III; Ministerio de Sanidad, Servicios Sociales e Igualdad, Grant/Award Number: PNSD2018-050; SUNY Downstate Medical

Center; Université de Bordeaux

\begin{abstract}
Clinical and preclinical findings have suggested a role of the endocannabinoid system (ECS) in the etiopathology of autism spectrum disorder (ASD). Previous mouse studies have investigated the role of ECS in several behavioral domains; however, none of them has performed an extensive assessment of social and communication behaviors, that is, the main core features of ASD. This study employed a mouse line lacking the primary endocannabinoid receptor $(\mathrm{CB} 1 \mathrm{r})$ and characterized ultrasonic communication and social interaction in $\mathrm{CB}^{-/-}, \mathrm{CB} 1^{+/-}$, and $\mathrm{CB} 1^{+/+}$males and females. Quantitative and qualitative alterations in ultrasonic vocalizations (USVs) were observed in CB1 null mice both during early development (i.e., between postnatal days 4 and 10), and at adulthood (i.e., at 3 months of age). Adult mutants also showed marked deficits in social interest in the three-chamber test and social investigation in the direct social interaction test. These behavioral alterations were mostly observed in both sexes and appeared more marked in $\mathrm{CB}^{-/-}$than $\mathrm{CB}^{+/-}$mutant mice. Importantly, the adult USV alterations could not be attributed to differences in anxiety or sensorimotor abilities, as assessed by the elevated plus maze and auditory startle tests. Our findings demonstrate the role of $\mathrm{CB} 1 \mathrm{r}$ in social communication and behavior, supporting the use of the $\mathrm{CB} 1$ full knockout mouse in preclinical research on these ASD-relevant core domains.
\end{abstract}

\section{Lay Summary}

The endocannabinoid system (ECS) is important for brain development and neural function and is therefore likely to be involved in neurodevelopmental disorders such as Autism Spectrum Disorder (ASD). Here we investigated changes in social behavior and communication, which are core features of ASD, in male

William Fyke and Marika Premoli contributed equally to this work. 
and female mice lacking the chief receptor of this system. Our results show that loss of this receptor results in several changes in social behavior and communication both during early development and in adulthood, thus supporting the role of the ECS in these ASD-core behavioral domains.

K E Y W O R D S

cannabinoid receptor, mouse models, phenotype, sex differences, ultrasounds

\section{INTRODUCTION}

Autism spectrum disorder (ASD) is a highly heterogeneous group of neurodevelopmental disorders characterized by a broad range of behavioral deficits (Harris et al., 2008; Shubrata et al., 2015); among these, alterations in social behaviors, especially in communication and social interest, are a major core component of ASD symptoms and provide a diagnostic criterion, together with the presence of repetitive/inflexible behaviors (Association, 2013). In the last years, an impressive impetus has been given to research on this neurodevelopmental disorder, with a special emphasis on preclinical animal models.

Despite the substantial and varied recent research efforts, the pathological mechanisms underlying ASD are far from being understood and therapeutic targets still need to be identified. It is known that ASD has a strong, though complex, genetic component, as it has been associated with a diverse array of copy number variants, chromosome duplications/ deletions and point mutations (De Rubeis \& Buxbaum, 2015; Folstein \& Rutter, 1977; Sebat et al., 2007; Velinov, 2019). With regard to brain function, a view of ASD as a connectivity disorder has emerged (Keown et al., 2017), since patients often present with heterogeneous patterns of functional and structural connectivity between and within brain regions which differ significantly from neurotypical individuals (Assaf et al., 2010; Nair et al., 2013).

The endocannabinoid system (ECS) is a promising candidate to understand the etiopathology of ASD and to provide novel therapeutic targets. It is mainly a retrograde inhibitory signaling pathway that includes the primary cannabinoid type-1 receptor $(C B 1 \mathrm{r})$ and the endogenous ligands, the endocannabinoids (Devane et al., 1992; Sugiura et al., 1995). It is a modulator of neuronal functions, as demonstrated by the abundance of $C B 1$ receptors in the brain (Mackie, 2005), and regulates synaptogenesis and neuronal interconnectivity during development (Berghuis et al., 2007; Mulder et al., 2008), all of them processes that are altered in ASD pathology (Pardo \& Eberhart, 2007). In addition, brain expression levels of $C N R 1$, the gene coding for $C B 1 \mathrm{r}$, increase during the late embryonic stage and peak during postnatal development (Marsicano \& Lutz, 1999).

Alterations in the expression of CBIr and other ECS components, as well as in their functionality, have been reported in ASD patients (Karhson et al., 2018; Smith et al., 2017) and in several animal models of ASD (reviewed by Zamberletti et al., 2017). Furthermore, recent clinical and preclinical studies support the efficacy of modulators of
ECS in treating ASD symptoms (Bar-Lev Schleider et al., 2019; Jung et al., 2012; Pretzsch et al., 2019). Studies with null mice $\left(C B 1^{-l-}\right)$ have demonstrated that $C B 1 \mathrm{r}$ plays a key role in the regulation of several behavioral responses (Haller et al., 2004; Litvin et al., 2013; Shonesy et al., 2018), including ASD-relevant repetitive (Terzian et al., 2011; Varvel \& Lichtman, 2002), and social behaviors (Haller et al., 2004; Haring et al., 2011; Litvin et al., 2013; Terzian et al., 2014). Mice lacking $C B 1 \mathrm{r}$ also have brain connectivity alterations, a neurological phenotype of ASD (Berghuis et al., 2007; Diaz-Alonso et al., 2012). However, to the best of our knowledge, no studies have been performed specifically on the role of CBIr and the ECS in modulating social communication, that is, one of the major domains altered in ASD.

The major form of social communication in mice is based on ultrasonic vocalizations (USVs), produced in the range above human hearing $(>20 \mathrm{kHz})$. USVs are produced throughout the life of the animal (Wohr \& Scattoni, 2013). Shortly after birth, mouse pups vocalize in response to separation from the mother to induce maternal retrieval (Brudzynski, 2009; Scattoni et al., 2009). These isolation-induced USVs represent one of the earliest social behaviors that can be analyzed quantitatively (Ricceri et al., 2007), and have functional similarities to cries produced by human infants, namely the induction of maternal care. During the first postnatal week, mouse pups increase their number of vocalizations, while a subsequent decrease follows during the second postnatal week, that is, a typical inverted U-shaped developmental pattern (Branchi et al., 2001; Sungur et al., 2016). At adulthood, male mice emit USVs during courtship interactions with females (Hammerschmidt et al., 2009; White et al., 1998). USVs are also produced in female to female interactions in a resident-intruder setting, possibly as a strategy of the resident to reduce the aggressiveness of the intruder (Maggio \& Whitney, 1985; Moles et al., 2007). Therefore, USVs may provide researchers with an accessible tool for modeling ASD-like communication deficits throughout development and adulthood (Crawley, 2004; Silverman et al., 2010), as demonstrated in several studies with mouse models of ASD (Belagodu et al., 2016; Gaudissard et al., 2017; Scattoni et al., 2008; Schmeisser et al., 2012; Spencer et al., 2011; Wohr et al., 2013; Wöhr et al., 2015).

Surprisingly, to our knowledge, ultrasonic communication in mice lacking $C B 1 \mathrm{r}$ has not been investigated yet, as only one USV study has been conducted in $C B 1^{-l-}$ pups, but within a chronic stress paradigm (Fride et al., 2005). Also, most behavioral studies - including 
those investigating social interest and interaction (Haller et al., 2004; Haring et al., 2011; Litvin et al., 2013; Terzian et al., 2014) - have so far focused exclusively on homozygous $\mathrm{CBI}^{-1-}$ male mice. Hence, little is known about potential "dosage" and sex-dependent effects of the $C B 1$ mutation on behavior, especially in relation to ASD-relevant phenotypes. Here we therefore examined ultrasonic communication in male and female $C B 1$ null mutants, homo $\left(\mathrm{CBI}^{-/-}\right)$or heterozygous $\left(\mathrm{CBI}^{+/-}\right)$for the mutation, during development (i.e., between postnatal days 4 and 10) and at adulthood (3 months). Both quantitative and qualitative analyses of spectrographic measurements were performed in order to provide with an extensive characterization of USVs in $C B 1$ null mutants and their WT littermates. To complete the assessment of ASD-relevant social phenotypes, social interest in the three-chamber test and social investigation towards a conspecific were also evaluated at adulthood. As confounding differences in anxiety (Fish et al., 2004; Simola \& Granon, 2019; Veronesi et al., 2017; Vivian \& Miczek, 1993) or sensori-motor abilities (Wada, 2017; Webber et al., 2013) may influence ultrasonic communication and social behavior, adult mice were also assessed in the elevated plus maze and auditory startle tests. The assessment of these behavioral confounders also contributed to the evaluation of the ASDrelevant phenotypes of the $\mathrm{CB} 1$ mouse line, since anxiety and enhanced auditory startle are recognized as additional ASD symptoms and are therefore often investigated in genetic mouse models of ASD (Crawley, 2007; Silverman \& Crawley, 2014).

\section{METHODS}

\section{Ethics approval}

All experimental procedures were in accordance with the European Communities Council Directive 2010/63/EEC, and approved by local ethical committee ("Comité d'Ethique pour l'experimentation animale de Bordeaux", CE 50) and the French Ministry ("Ministere de l'enseignement superieur de la recherché et de l'innovation").

\section{Animals}

All experiments were performed in homozygous $C B 1$ null mutant $\left(C B 1^{-/-}\right)$mice with a targeted deletion of $C N R I$ gene and their heterozygous $\left(C B 1^{+-}\right)$and wildtype $\left(\mathrm{CBI}^{+/+}\right)$littermates. Mice were obtained from breeders on a $\mathrm{C} 57 \mathrm{BL} / 6 \mathrm{~N}$ congenic background, generated as previously reported (Marsicano et al., 2002). $C B 1^{+/-}$virgin males and females were paired for breeding in a temperature- $\left(21 \pm 1^{\circ} \mathrm{C}\right)$ and humidity- $(40 \%)$ controlled animal facility (lights on at 07:00 am); approximately two weeks afterwards, pregnant females were individually housed and left undisturbed. The day of birth was considered as postnatal day (PND) 0 .

Three batches of mice were used, as described in detail in Table 1: one batch (36 males and 36 females) was tested for USVs during development between PND 4 and 10 (Experiment 1a); a subgroup of the same batch (24 males and 24 females) was tested again for USVs at adulthood (Experiment 1b). A second batch of adult mice (23 males and 26 females) underwent the tests of social interest in the three-chamber apparatus and of direct social interaction with an adult female. A third batch of mice (34 males and 27 females) was tested at adulthood in the elevated plus maze followed by the auditory startle test. Overall, our sample size (calculated according to the resource equation method Charan \& Kantharia, 2013) combined with the statistical approach including parametric methods and repeated measures was in line with the "classical" (Still, 1982) and more recent (Charan \& Kantharia, 2013; Festing \& Altman, 2002) guidelines for

T A B L E 1 Experimental plan of the study

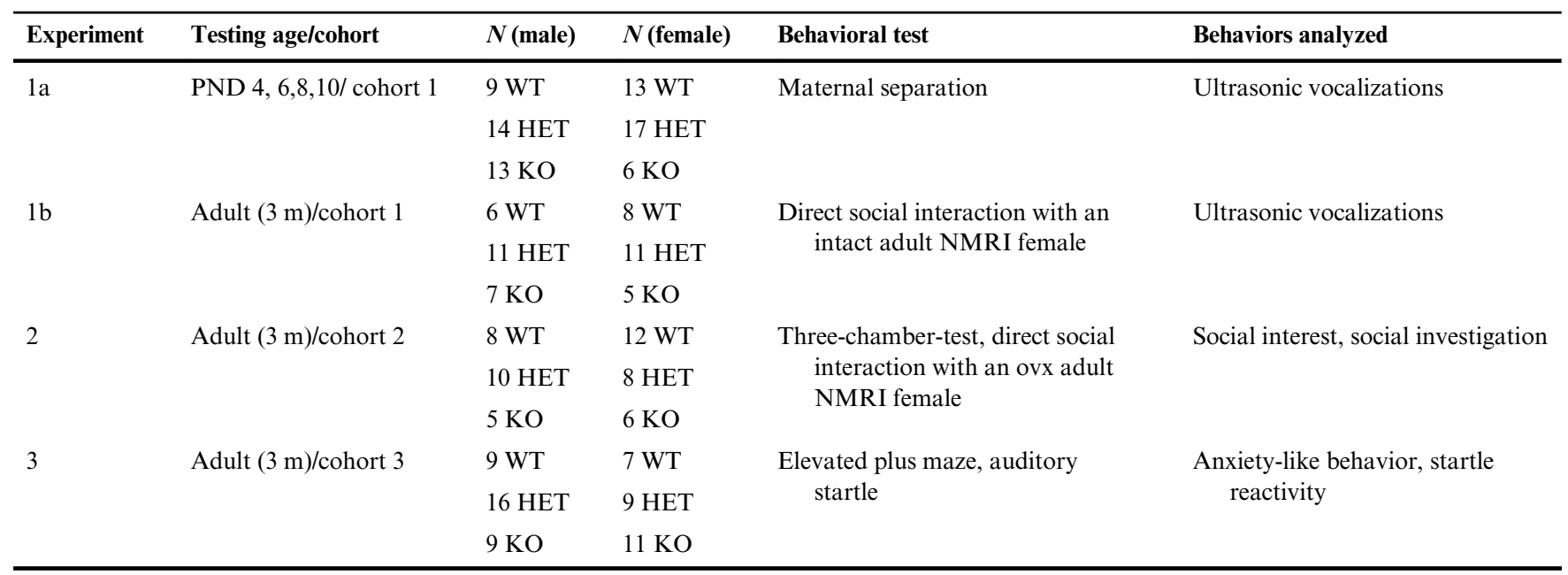

Note: A subgroup of the cohort used for Experiment 1a was re-assessed in Experiment 1b, while separate cohorts of adult mice underwent Experiments 2 and 3.

Experiment la used male and female pups obtained from 11 litters, including all genotypes.

Abbreviations: Ovx, ovariectomized female; PND, postnatal day. 
data analysis in animal studies. Nonetheless, we were partially limited in the sample size by the following factors; (a) litters including all three genotypes were preferentially selected in the study, (b) primiparous females had to be used for breeding in all experiments (as commonly done in studies including pup USVs, since previous maternal experience may affect USV's characteristics, e.g., Francia et al., 2006), and (c) breeding was based on heterozygous crossings as suggested by guidelines for mouse studies on behavioral genetics to control for maternal effects (Crusio, 1996; Crusio et al., 2009).

Experiment 1a used male and female pups obtained from 11 litters, including as much as possible all three genotypes $\left(\mathrm{CBI}^{-1-}, \mathrm{CBI}^{+/-}\right.$, and $\left.\mathrm{CBI}^{+/+}\right)$. The approach used here, including a high number of litters together with the use of WT and mutant littermates and testing all litter members without sampling, has been suggested as the most appropriate to protect from the risk of false positives related to litter effects, by past (Chiarotti et al., 1987; Zorrilla, 1997) and recent (Jimenez \& Zylka, 2021) guidelines on mouse neurodevelopmental studies. On PND 4 pups were marked after testing by paw tattoo, using a non-toxic odor-less tattoo ink (Ketchum permanent Tattoo Inks green paste, Ketchum MFG. Co.), as previously described (Wohr et al., 2011; Yang et al., 2012). This procedure is routinely used for pups' marking and identification, as it is associated with minimal stress and pain. On the same day tail samples were collected for DNA extraction and subsequent PCR assessment of the genotypes as previously described (Marsicano et al., 2002). Mice were weaned at 3 weeks of age (PND 21), housed in same-sex cages in groups of 3-5 mice/cage in polycarbonate standard cages $(33 \times 15 \times 14 \mathrm{~cm}$ in size; Tecniplast). Mice were left undisturbed until Experiment $1 \mathrm{~b}$ began, that is, at 3 months of age. Animals for Experiments 2 and 3 were bred and housed as described from Experiment 1, but they were left undisturbed until PND 21, when they were weaned, identified, and genotyped and they were all tested at 3 months of age.

Stimulus mice used for the adult assessment of USVs (Experiment 1b) and of social interest and investigation (Experiment 2) were adult (10 weeks of age) female NMRI mice (Janvier, Le Genest-Saint-Isle), as this strain is commonly employed in social studies (Moles et al., 2000; Moles et al., 2007) since (a) it is characterized by high levels of sociability, (b) is an albino strain, so it facilitates the behavioral analysis during social encounters with B6 mutants, and (c) it has been used in several social tests with mouse models of ASD (Gaudissard et al., 2017; Gauducheau et al., 2017; Hébert et al., 2014; Oddi et al., 2015; Pietropaolo et al., 2014; Pietropaolo, Guilleminot, et al., 2011) and other neurodevelopmental and neurological disorders (Pietropaolo et al., 2015; Pietropaolo, Delage, et al., 2011; Pietropaolo et al., 2012), as well as in mouse social studies with CB1r antagonists (Pietropaolo et al., 2020). They were housed in groups of 3-4 per cage in the same conditions used for test subjects and left undisturbed for 2 weeks before being used in behavioral tests. We employed intact and ovariectomized NMRI stimulus females, for the adult assessment of USVs (Experiment 1b) and social interest/investigation (Experiment 2), respectively. This allowed us to be in line with most ASD-relevant previous studies assessing USVs in adult male and female mice, including a recent mouse study on USVs and pharmacological inhibition of CB1r (Pietropaolo et al., 2020). These USV experiments mostly employed intact stimulus females (Caruso et al., 2020), concomitantly assessing their estrous phase, as controversial findings have been reported on the impact of estrous phase on USVs (Hanson \& Hurley, 2012; Kim et al., 2016; Moles et al., 2007; Nyby et al., 1979; Yang et al., 2015). Hence, we have also used intact female stimuli for USV adult assessment, taking into account their estrous phase as well as that of the female resident in the statistical analysis of the data. The choice of an ovariectomized female for the three-chamber and direct social interaction tests allowed us to directly compare our findings with those from a previous study with CB1 male mutants (Terzian et al., 2014), concomitantly avoiding the potential impact of estrous phase on social interest/ interaction and limiting the occurrence of sexual behaviors due to the longer duration of the testing session of direct social interaction. All animal cages were covered by a stainless metal wired lid, provided with sawdust (SAFE, Augy) and ad libitum food and water; they were provided with nesting material as environmental enrichment (Cotton Nestlets).

\section{Behavioral testing}

As mentioned above, three behavioral experiments were carried out, using three independent cohorts of mice (Table 1). First, ultrasonic communication was evaluated on PND 4, 6, 8, and 10 in response to maternal separation (Experiment 1a), and again at adulthood in response to an adult female intruder (Experiment 1b). Second, adult social interest and investigation were assessed respectively in the three-chamber and direct social interaction tests (Experiment 2). Finally, adult mice were tested for anxiety-like behavior in the elevated plus maze and for auditory startle response, that is, two behavioral confounding variables potentially acting on ultrasonic communication and social behavior (e.g., Simola \& Granon, 2019; Webber et al., 2013). All behavioral procedures were based on experimental protocols used in our previous studies on genetic mouse models of ASD (Gaudissard et al., 2017; Gauducheau et al., 2017; Hébert et al., 2014; Oddi et al., 2015; Pietropaolo et al., 2014; Pietropaolo, Guilleminot, et al., 2011; Zhang et al., 2014). Behavioral tests were performed in adult mice with a $48 \mathrm{~h}$ interval between subsequent tests, and they were carried out by experimenters blind to animals' genotypes. Except for pups' assessment, male and female mice were tested on 
separate days, in order to avoid olfactory interference in the testing environment.

\section{Experiment 1a: Assessment of isolation-induced} USVs in pups

USVs of $\mathrm{CBI}^{-/-}, \mathrm{CBI}^{+/-}$, and $\mathrm{CBI}^{+/+}$littermates were repeatedly assessed on PND 4, 6, 8, and 10, during a 3-min daily session at room temperature $\left(22^{\circ} \mathrm{C}-24^{\circ} \mathrm{C}\right)$. Pups were taken individually from the nest in a random sequence and placed into a glass container $(10 \times 8 \times 7 \mathrm{~cm}$; open surface $)$, containing clean bedding material $(3 \mathrm{~cm})$. USVs were captured by an UltraSoundGate Condenser Microphone CM 16 (Avisoft Bioacoustics) placed $20 \mathrm{~cm}$ above the bedding. The microphone used is sensitive to frequencies of 15 to $180 \mathrm{kHz}$ with a flat frequency response $( \pm 6 \mathrm{~dB})$ between 25 and $140 \mathrm{kHz}$. It was connected via an UltraSoundGate 116 USB audio device (Avisoft Bioacoustics) to a personal computer, where acoustic data were recorded with a sampling rate of $250 \mathrm{kHz}$ in 16-bit format by Avisoft RECORDER (version 2.97; Avisoft Bioacoustics). At the end of the 3-min session, each pup was weighed and identified, while the container was cleansed with $70 \%$ ethanol solution and filled with clean bedding.

For acoustic analyses, recordings were transferred to Avisoft SASLab Pro (Version 5.20; Avisoft) and a Fast Fourier transformation was applied (512 FFT length, $100 \%$ frame, Hamming window, and $75 \%$ time window overlap). Call detection was provided by an automatic threshold-based algorithm and the accuracy of call detection by the software was verified manually by an experienced user. Based on previous studies (Wohr et al., 2011), the number of USVs was computed, as well as their mean duration, peak frequency and peak amplitude. In addition, call subtypes were determined by density plots depicting the distribution of total calls for each genotype at peak frequency versus peak amplitude, peak frequency versus duration, and peak amplitude versus duration, as described in details elsewhere (Mosienko et al., 2015; Wohr, 2014).

\section{Experiment 1b: Assessment of interaction- induced USVs in adults}

$\mathrm{CBI}^{-1-}, \mathrm{CBI}^{+/-}$, and $\mathrm{CBI}^{+/+}$male and female littermates were then tested at adulthood in a $33 \times 15 \times 14 \mathrm{~cm}$ plastic cage with $3 \mathrm{~cm}$ of sawdust and a metal flat cover. Male experimental subjects were habituated to this apparatus for $15 \mathrm{~min}$ prior to testing, while female subjects were isolated in the testing cage for $72 \mathrm{~h}$, in order to induce a status of resident in adult females and therefore promote the emission of USVs toward an adult female intruder (Moles et al., 2007). An unfamiliar stimulus female mouse (an adult intact NMRI female) was then introduced into the testing cage of either male or female subjects and left there for $3 \mathrm{~min}$. Previous studies have shown that in these experimental settings USVs are mainly emitted by the male mouse in the male-female interaction (Wang et al., 2008; Warburton et al., 1989; Whitney et al., 1973), and by the female resident in the female-female interaction (Maggio \& Whitney, 1985; Moles et al., 2007). The ultrasonic microphone previously described was mounted $2 \mathrm{~cm}$ above the cover of the testing cage; subsequent scoring of USV parameters was performed following the same procedures described for experiment $1 \mathrm{a}$.

The estrus phase of adult females was assessed by analysis of vaginal smears (Caligioni, 2009) performed on the testing day in both the experimental subjects and NMRI stimulus mice. The evaluation of $C B 1^{-1-}, C B 1^{+--}$, and $C B 1^{+/+}$females was conducted after their testing, in order to minimize the potential stress effects of the manipulation necessary for determining the estrous phase. Stimulus NMRI females were approximately half in diestrus and half in estrus phases, and their assignment to social encounters was equally distributed between genotypes and sexes. The estrus phase of experimental female subjects included proestrus, estrus and diestrus, following a distribution that was balanced across genotypes $\left(C B 1^{-1-}\right.$ females included 2 in proestrus, 2 in estrus and 1 in diestrus; $C B 1^{+-}$were 4 in proestrus, 4 in estrus and 3 in diestrus; and $C B 1^{+/+}$included 3 in proestrus, 2 in estrus and 3 in diestrus).

\section{Experiment 2: Assessment of social interest and social investigation in adult mice}

Mice of a second cohort were assessed first in the threechamber test for social interest and $48 \mathrm{~h}$ later in the direct social interaction; both tests used an ovariectomized NMRI adult female as the social stimulus, since the estrous phase of the stimulus animal is known to affect social interest and investigation (Baudoin et al., 1991; Liu et al., 2010). The estrus phase of experimental female subjects was assessed as described in Experiment 1b, and no differences in the distribution of estrous phases were found between genotypes.

\section{Three-chamber test for social interest}

The three-chamber apparatus was made of transparent Plexiglas (its detailed description was provided elsewhere Gauducheau et al., 2017). Each side compartment contained a perforated stimulus cage $(8 \times 8 \times 15 \mathrm{~cm})$ placed at a distance of $5.5 \mathrm{~cm}$ from the side walls.

Each experimental animal was placed in the middle of the central compartment and allowed to explore the whole apparatus for two trials of $5 \mathrm{~min}$ each (Pietropaolo, Guilleminot, et al., 2011). On the first trial the stimulus cages were empty and the experimental mouse was left undisturbed to explore the apparatus and habituate to the testing environment. At the end of this trial, the experimental mouse was confined in the central compartment using two transparent Plexiglas magnetic doors for $40 \mathrm{~s}$. 
On the second trial, a stimulus mouse (an adult ovariectomized NMRI female) was introduced in one of the stimulus cages, while a novel object (a glass red cylinder) was introduced in the other one. The position of the social stimulus and of the object was counterbalanced between genotypes. The apparatus and the stimulus cages were cleansed with $70 \%$ ethanol solution at the end of the second testing trial. The time spent in each of the side compartments containing the stimulus cages was computed from the video files obtained from a camera placed above the center of the apparatus. An experimenter blind to stimulus position and animals' sex and genotypes performed the analysis using Observer XT (version 7, Noldus).

\section{Direct social interaction with an adult female}

Each experimental animal was confined in one of the side compartments of the three-chamber apparatus and an unfamiliar stimulus NMRI female was introduced and left for $10 \mathrm{~min}$. Testing sessions were recorded by a camera placed on the side of the compartment and videos analyzed with Observer XT. One observer who was unaware of the genotype and sex of the animals scored the behavior of the test mice, quantifying the time spent performing affiliative behaviors (Gaudissard et al., 2017; Gauducheau et al., 2017; Oddi et al., 2015; Pietropaolo et al., 2014; Pietropaolo, Guilleminot, et al., 2011), that is, sniffing the head and the snout of the partner, its anogenital region, or any other part of the body; contact with partner through traversing the partner's body by crawling over/under from one side to the other or allogrooming. Nonsocial activities were also measured: rearing (standing on the hind limbs sometimes with the forelimbs against the walls of the cage); digging; self-grooming (the animal licks and mouths its own fur). The testing session was analyzed in 5-min bins, in order to assess social habituation, that is, the expected time-dependent decrease in affiliative behaviors that is known to occur after the initial minutes of a social encounter and is often altered in mouse models of ASD (Pietropaolo et al., 2014; Shah et al., 2013). Furthermore, the separate analysis of the first $5 \mathrm{~min}$ allowed a better comparison of our results with those obtained from other studies on social interaction/interest tests, since short testing session (typically between 3 and 5-min-duration) are most commonly employed in experiments on both male and female mice (e.g., Moles et al., 2007; Nadler et al., 2004; Ricceri et al., 2007).

\section{Experiment 3: Assessment of potential confounding nonsocial behavioral alterations in adult mice}

Mice of a third cohort were assessed first for anxiety-like behavior in the elevated plus maze and $48 \mathrm{~h}$ later in for auditory startle response. The estrus phase of female subjects was assessed as described in Experiment $1 \mathrm{~b}$ at the end of each behavioral test, and no differences in the distribution of estrous phases were found between genotypes. Prior to each test, behavioral equipment was cleaned using a $70 \%$ ethanol solution, followed by water, and dried with paper towels.

\section{Elevated plus maze}

The maze described in details elsewhere (Pietropaolo \& Crusio, 2009; Pietropaolo, Guilleminot, et al., 2011) was placed $55 \mathrm{~cm}$ above floor level, in a quiet testing room with diffuse dim lighting. A digital camera was mounted above the maze, and images were transmitted to a PC running the Ethovision (Version 11, Noldus Technology) tracking system. To begin a trial, the mouse was gently placed in the central square with its head facing one of the open arms and allowed to explore freely for $5 \mathrm{~min}$. We measured the percent time in open arms as (time $_{(\text {open }}$ arms) $/$ time $_{(\text {open }}+$ closed arms) $)$ x 100 . Total distance moved was also assessed.

\section{Auditory startle response}

The whole-body startle response to low intensity auditory stimuli was measured using startle response boxes (SRLAB, San Diego Instruments), as described in details elsewhere (Gaudissard et al., 2017). Briefly, mice were habituated to the boxes for $24 \mathrm{~h}$ prior to testing for $5 \mathrm{~min}$ to reduce stress. On the days of testing, mice were presented with pulses of 20-ms duration and varying intensity: +6 , $+12,+18$, and $+24 \mathrm{~dB}$ over a white background noise at $66 \mathrm{~dB}$ (namely 72, 78, 84, and $90 \mathrm{~dB}$ ). Startle reactivity was assessed by the scores obtained for the mean of trials for each stimulus level presented.

\section{Statistical analysis}

Data from experiment 1a were analyzed using a $3 \times 2 \times 4$ parametric analysis of variance (ANOVA) with genotype and sex as between-subject factors, and day as within-subject factor. For all other experiments, data from males and females were analyzed separately using a one way ANOVA with only genotype as between-subject factor. These separate analyses were necessary as male and female mice had to be tested (a) on different days to avoid odor interference in all experiments, and (b) using a different experimental protocol to allow USV detection in Experiment $1 \mathrm{~b}$.

Within-subject factors, that is, stimulus compartment, 5-min-bins, stimulus intensities, were added to the ANOVAs of the data of social interest, social interaction, and auditory startle. Post hoc comparisons using Fisher's PLSD test were performed when appropriate. To better conform to the assumptions of parametric ANOVA, a natural logarithmic transformation was applied to the startle reactivity scores (Experiment 3). Data from the density plots did not undergo statistical analysis, but were used to obtain a qualitative three-dimensional evaluation of USV data, as in previous studies (Mosienko 
et al., 2015; Wohr, 2014). All statistical analyses were performed using SPSS Statistics Version 25 and GraphPad Prism 8 (GraphPad Software).

\section{RESULTS}

\section{Experiment 1a: Assessment of isolation-induced USVs in mouse pups}

CB1 mutation affected the body weight of mouse pups and this effect was detected only in females, where it differed across postnatal days (interaction sex $\mathrm{x}$ genotype $\mathrm{x}$ day: $\mathrm{F}_{6,198}=3.58, p<0.01$, and interaction genotype $\mathrm{x}$ day in females: $\mathrm{F}_{6,33}=3.596, p<0.05$; Figure 1). On PND 4, both $C B 1^{+l-}$ and $C B 1^{-l-}$ females weighted less than their $C B 1^{+/+}$littermates, and this difference was still found on PND 10, but for $C B 1^{-1-}$ pups only (post hoc, $p<0.05$ ). No significant genotype difference in body weight gain emerged in male pups (genotype and interaction genotype $\mathrm{x}$ day, all n.s).

All USV parameters followed a developmental pattern, with changes across PNDs. As expected, the number of USVs emitted by pups of both sexes showed a peak occurring on PND 4 and 6 followed by a decrease on PND 8 and PND 10 (day effect: $\mathrm{F}_{3,198}=44.272$, $p<0.0001$; Figure 2a,b). This pattern was altered in $C B 1$ mutants, with slight differences between sexes (genotype $\mathrm{x}$ day: $\mathrm{F}_{6,198}=2.645, p<0.05$; sex $\mathrm{x}$ genotype $\mathrm{x}$ day: $\left.\mathrm{F}_{6,198}=2.309, p<0.05\right)$. The most prominent decrease was observed in males on PND 10, and it was less marked in $C B 1^{-1-}$ littermates only (genotype $\mathrm{x}$ day in males $\mathrm{F}_{6,99}=2.674, p<0.05$; post hoc: $p<0.05$; Figure 2a), while in females it was observed on PND 8 and it was attenuated in both $\mathrm{CBI}^{+/-}$and $C B 1^{-1-}$ animals (genotype $\mathrm{x}$ day in females $\mathrm{F}_{6,99}=2.95, p<0.05$; post hoc: $p<0.05$; Figure $2 \mathrm{~b}$ ).

A similar pattern was detected also on USV duration, with a peak occurring on PND 4-6 and a reduction afterwards (day effect: $\mathrm{F}_{3,198}=19.13, p<0.0001$; Figure 2c, d). This pattern was more marked in male than in female mice, with a more dramatic decrease in call duration on the last days in males (interaction sex $\mathrm{x}$ day: $\left.\mathrm{F}_{3,198}=5.67, p<0.01\right)$, where it tended to be attenuated in $C B 1^{-1-}$ mice (interaction genotype $\mathrm{x}$ day in males: $\mathrm{F}_{6,99}=2.75, p<0.05$; post hoc: $p<0.05$, Figure $2 \mathrm{c}$; in females, genotype effects or its interactions: all n.s., Figure 2d).

The peak frequency of the calls increased on PND 8 and 10, and this pattern differed between sexes and genotypes (genotype $\mathrm{x}$ sex: $\mathrm{F}_{2,66}=3.07, p=0.05$; Figure 2e,f). The highest increase in peak frequencies was observed in males on PND10 and this was markedly reduced in $\mathrm{CBI}^{-/-}$pups only (interaction genotype $\mathrm{x}$ day in males: $\mathrm{F}_{6,33}=10.463, p<0.0001$; Figure 2e), while in females it was detected already on PND 8, and it was almost absent in both $C B 1^{-1-}$ and $C B 1^{+/-}$pups (interaction genotype $\mathrm{x}$ day in females: $\mathrm{F}_{6,33}=4.989, p<0.05$; Figure 2f). The peak amplitude of USVs tended instead to decrease (softer calls) on PND8 and PND10 (day effect: $F_{3,198}=155.959, p<0.0001$; Figure $2 \mathrm{~g}$,h), with no differences between sexes and genotypes (all effects and interactions, n.s.).

In a subsequent detailed analysis based on 28,756 calls emitted by $C B 1^{+/+}$pups, 44,724 calls by $C B 1^{+/-}$ pups, and 31,452 calls by $C B 1^{-1-}$ pups, different clusters of isolation-induced USVs were revealed by density plots (Figure 3). In $\mathrm{CBI}^{+/+}$mice a single cluster was identified on PND 4, most USVs being characterized by peak frequencies between 60 and $70 \mathrm{kHz}$. On PND 6, a second cluster between 80 and $100 \mathrm{kHz}$ appeared, became more prominent on PND 8, and included most USVs as a single cluster on PND10. A similar pattern was observed in $\mathrm{CBI}^{+-}$and $C B 1^{-/-}$pups except on PND10, when both mutants continued to produce the majority of their USVs in two distinguishable clusters. This effect was found in both male and female mice.

\section{Experiment 1b: Assessment of interaction- induced USVs in adult mice}

The CB1 mutation affected the number of USVs produced at adulthood by both males and females (genotype
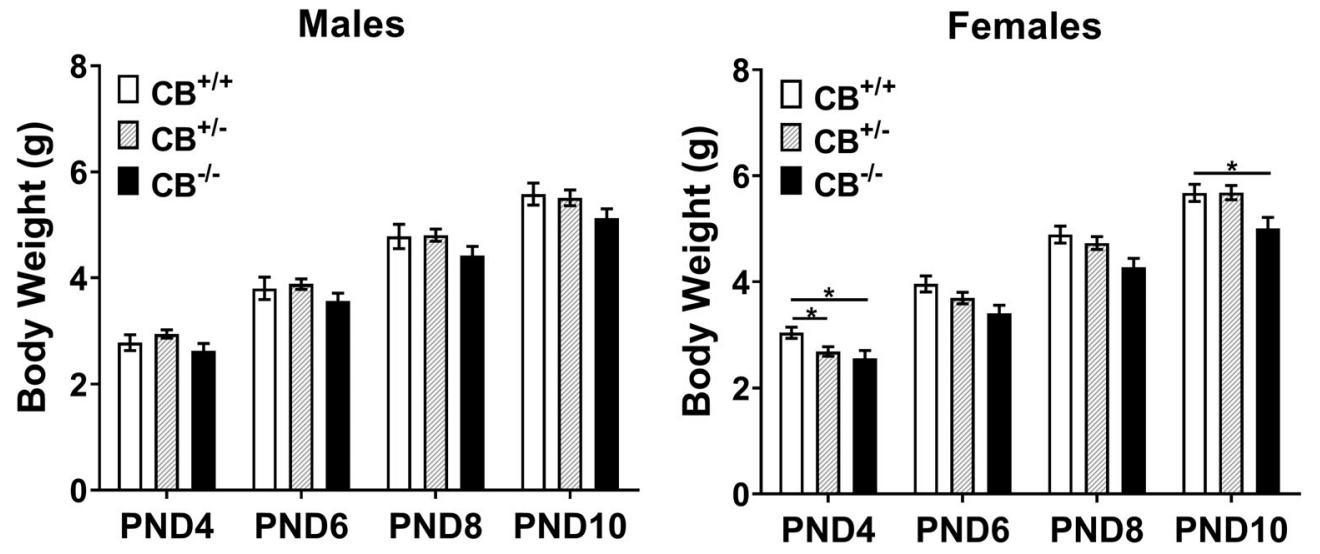

F I G UR E 1 Effects of the $C B 1$ null mutation on body weight during development (Experiment 1a). ${ }^{*}=p<0.05 . \mathrm{N}$ (males) $=9\left(C B 1^{+/+}\right)$, $14\left(C B 1^{+/-}\right), 13\left(C B 1^{-l-}\right) \cdot \mathrm{N}$ (females) $=13\left(C B 1^{+/+}\right)$, $17\left(\mathrm{CBI}^{+--}\right), 6\left(\mathrm{CBI}^{-/-}\right)$. Male and female pups were obtained from 11 litters, including all three genotypes (CB1-I-, CB1+l-, and $\mathrm{CB} 1+/+)$. Data are mean $\pm S E M$ 
F I G U R E 2 Effects of the $C B 1$ null mutation on ultrasonic vocalization (USV) during development in mouse pups. Isolation-induced USVs were analyzed in terms of quantitative $(\mathrm{a}, \mathrm{b})$ and qualitative $(\mathrm{C}$ to $\mathrm{H})$ parameters. $*=p<0.05 . \mathrm{N}$ (males) $=9\left(\mathrm{CBI}^{+/+}\right), 14\left(\mathrm{CBI}^{+/-}\right)$, $13\left(C B 1^{-l-}\right) . \mathrm{N}$ (females) $=13\left(C B 1^{+/+}\right)$, $17\left(\mathrm{CBI}^{+-}\right), 6\left(\mathrm{CBI}^{-/-}\right)$. All pups were obtained from 11 litters, including all genotypes. Data are mean $\pm S E M$

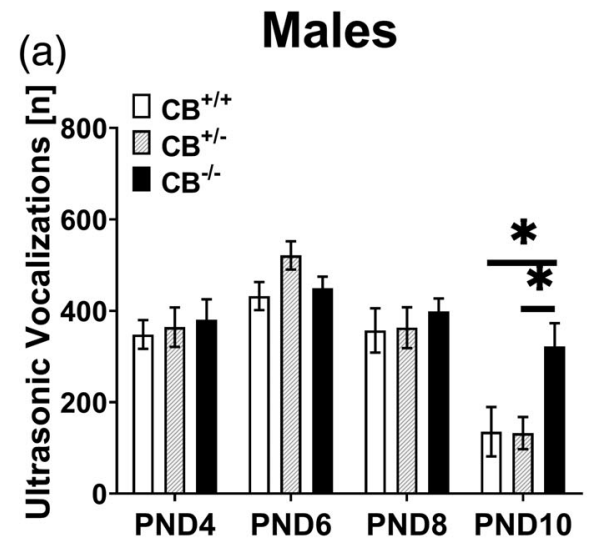

(b)

Females

(c)

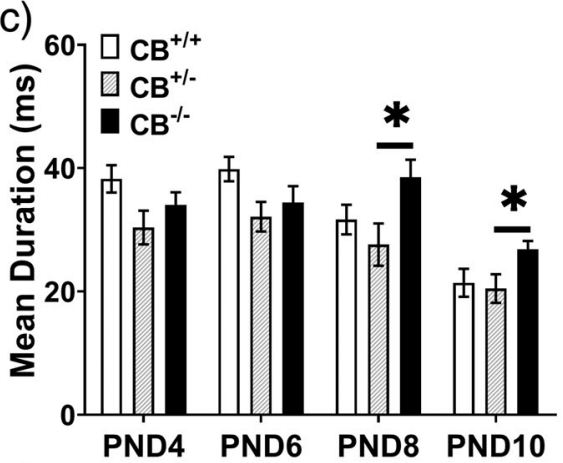

(e)

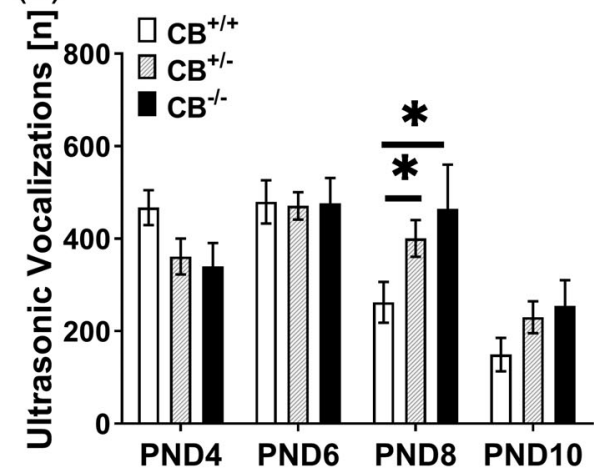

(d) ${ }_{60}$

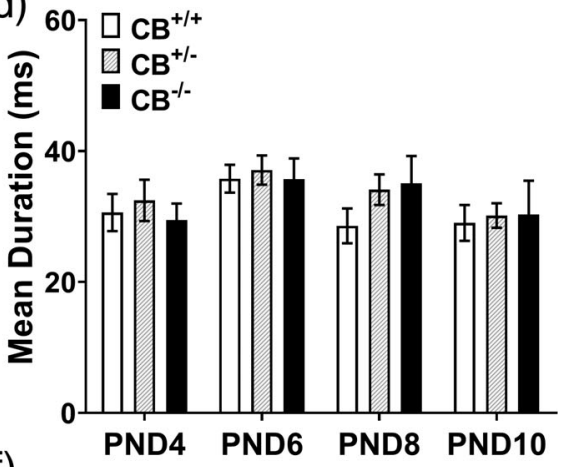

(f)

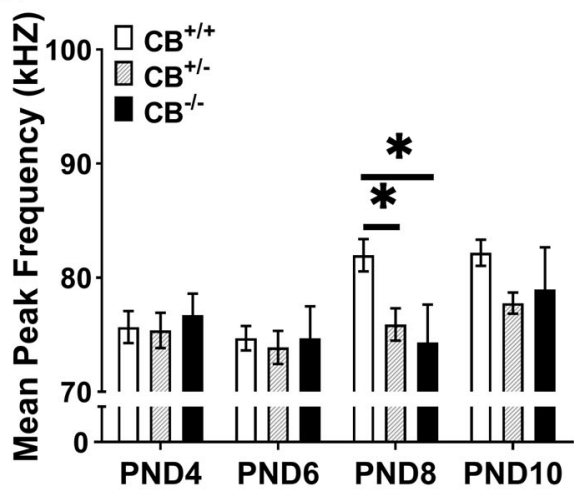

(h)

(g)

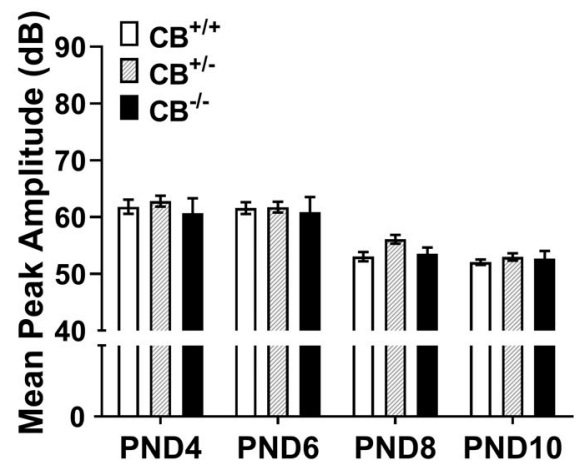

effect, respectively: $\mathrm{F}_{2,21}=15.89,4.06$, and $p<0.05$; Figure 4a,e), with $C B 1^{-1-}$ mice emitting less USVs than their $\mathrm{CBI}^{+/+}$and $\mathrm{CBI}^{+/-}$littermates (post hoc: $p<0.05$ ). No differences in other parameters, including duration, peak frequency and peak amplitude were detected in either sex (all genotype effects, n.s.; Figure 4b-d, f-h).
Stimulus NMRI females were approximately half in diestrus and half in estrus phases, and their assignment to social encounters was balanced between genotypes and sexes. In males, no significant main effect of the estrous phase of the stimulus females $\left(\mathrm{F}_{1,18}=1.24,0.51,0.03\right.$, 1.17 , for number, mean duration, peak amplitude and 

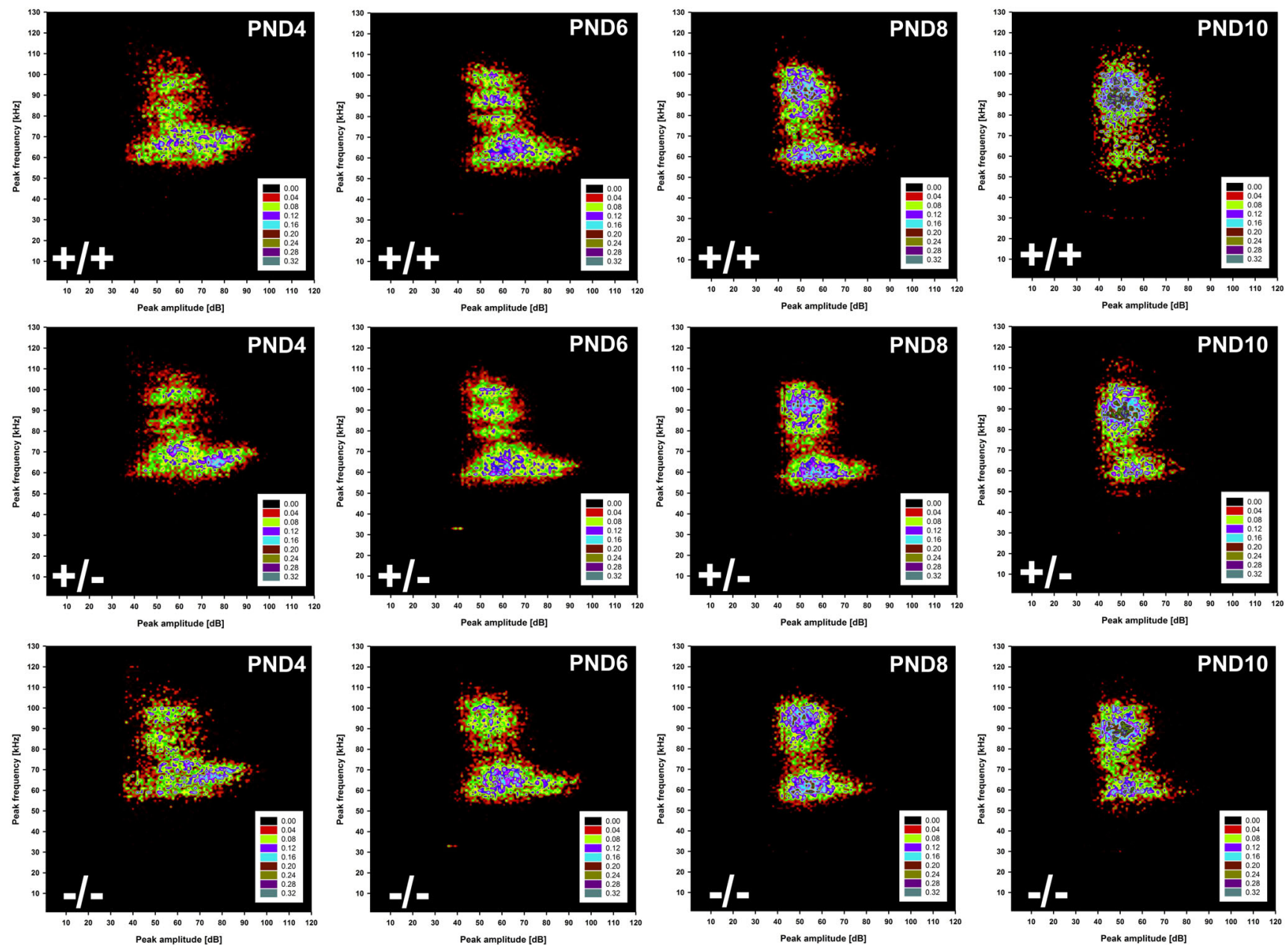

F I G U R E 3 Density plots depicting the distribution of individual ultrasonic vocalizations by postnatal day (PND) in mouse pups. Distribution of individual USVs depending on peak frequency in $\mathrm{kHz}$ and amplitude in $\mathrm{dB}$ in $C B 1^{+/+}, C B 1^{+/-}$, and $C B 1^{-1-}$ littermates. Color coding reflects frequency in percentages. Pooled data for both sexes are represented, as no difference between males and females was detected

peak frequency, all n.s.) or its interaction with genotype $\left(\mathrm{F}_{2,18}=0.09,1.02,0.79,0.73\right.$, for number, mean duration, peak amplitude, and peak frequency, all n.s.) was detected on any USV parameter. In females, similar results on the impact of the estrous phase of the stimulus animals were obtained, with no main effect $\left(\mathrm{F}_{1,18}=0.03,0.01,0.62,0.05\right.$, for number, mean duration, peak amplitude and peak frequency, all n.s.) or interaction with genotype $\left(\mathrm{F}_{2,18}=0.03\right.$, $1.13,1.4,0.83$, for number, mean duration, peak amplitude and peak frequency, all n.s.). The estrus phase of experimental female subjects included proestrus, estrus, and diestrus, following a distribution that was mostly balanced across genotypes. The estrous phase of the experimental subjects did not induce any significant main effect $\left(\mathrm{F}_{2,15}=0.29,0.94,1.14,1.12\right.$,for number, mean duration, peak amplitude and peak frequency, all n.s.) or interaction with genotype $\left(\mathrm{F}_{4,15}=0.07,0.69,0.93,1.89\right.$, for number, mean duration, peak amplitude and peak frequency, all $\mathrm{n}$. s.) on all considered USV parameters.
As in Experiment 1a, a detailed analysis (Figure 5) was performed in males based on 4106 calls for $\mathrm{CBI}^{+/+}$, 11,289 calls for $C B 1^{+/-}, 1082$ calls for $C B 1^{-1-}$ mice, and in females based on 9237 calls for $C B 1^{+/+}, 8600$ calls for $\mathrm{CBI}^{+/-}$, and 1283 calls for $\mathrm{CBI}^{-1-}$ mice. In $\mathrm{CB1^{+/+ }}$ males the majority of calls were clustered between 70 and $85 \mathrm{kHz}$ for peak frequency and 5 to $25 \mathrm{~ms}$ for the mean duration; while $\mathrm{CBI}^{+/-}$littermates exhibited a similar pattern, $C B 1^{-1-}$ males showed substantially more variation in their calls in both mean peak frequency and duration, with the majority of calls occurring in clusters between 65 and $90 \mathrm{kHz}$ and durations between 5 and $50 \mathrm{~ms}$. In $\mathrm{CB}^{+/+}$females most USVs were distributed in two clusters, one between 70 and $75 \mathrm{kHz}$ and another between 80 and $85 \mathrm{kHz}$, both with durations between 5 and $40 \mathrm{~ms}$. These two clusters were less distinguishable in $\mathrm{CB}^{+/-}$females, and tended to disappear in $\mathrm{CBI}^{-/-}$ mice, emitting USVs with a wider variation in both mean peak frequency and duration. 

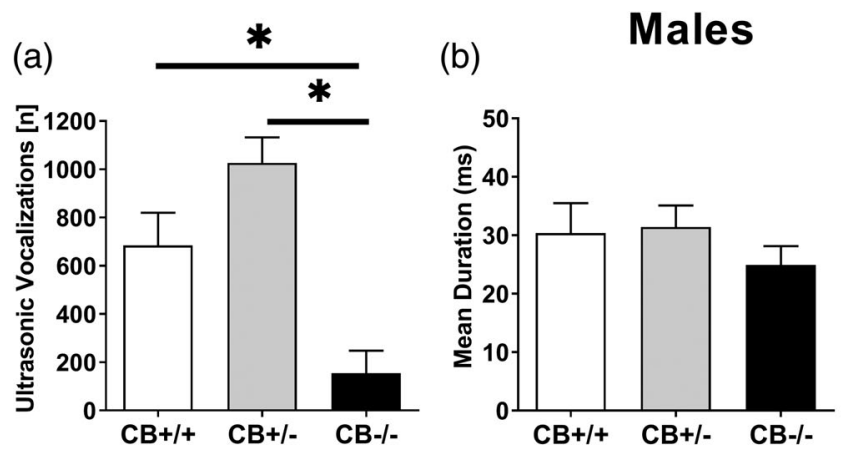

(c)

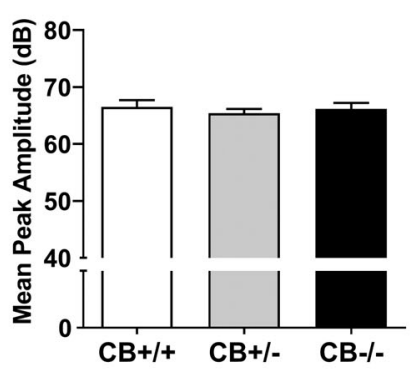

Females

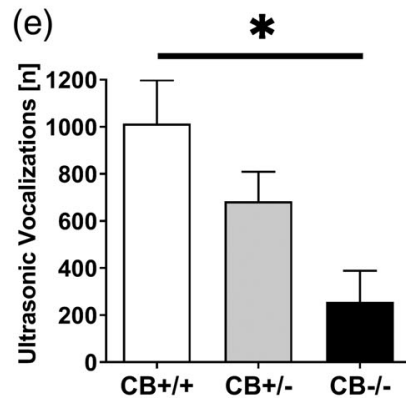

(f)

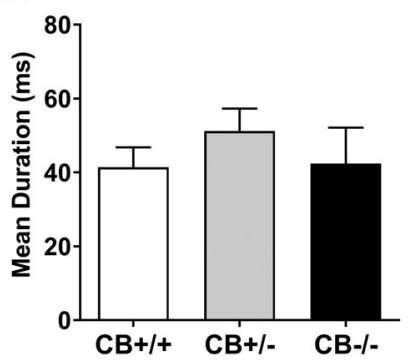

(g)

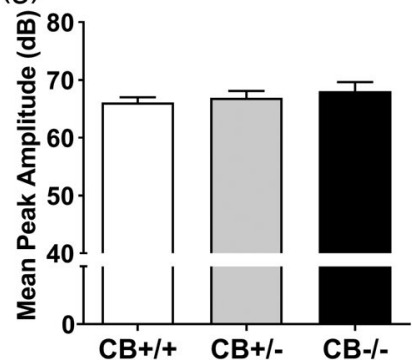

(d)

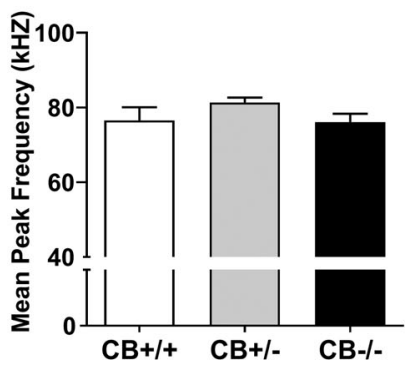

(h)

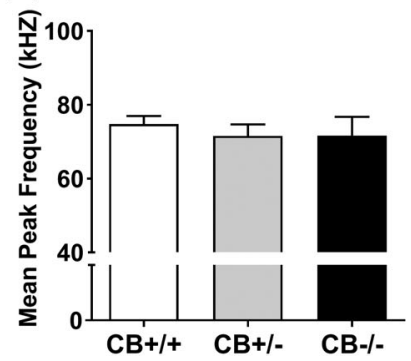

F I G U R E 4 Effects of the $C B 1$ null mutation on interaction-induced ultrasonic vocalization (USV) in adult mice. USVs were analyzed in male and female mice during a 3-min session of direct social interaction with an intact NMRI stimulus female. USVs were analyzed in terms of quantitative $(\mathrm{a}, \mathrm{e})$ and qualitative $(\mathrm{b}, \mathrm{c}, \mathrm{d}, \mathrm{f}, \mathrm{g}, \mathrm{h})$ parameters. ${ }^{*}=p<0.05 . \mathrm{N}($ males $)=6\left(C B 1^{+/+}\right), 11\left(C B 1^{+/-}\right), 7\left(C B 1^{-/-}\right) . \mathrm{N}(\mathrm{females})=8$ $\left(C B 1^{+/+}\right), 11\left(C B 1^{+/-}\right), 5\left(C B 1^{-l-}\right)$. Data are mean $\pm S E M$

\section{Experiment 2: Assessment of social interest and social investigation in adult mice}

One $\mathrm{CBI}^{+/-}$and a $\mathrm{CBI}^{+/+}$mouse, both females, were excluded respectively from the analysis of the data of the three chamber and direct social interaction tests because of problems in video recording (the precise $\mathrm{n}$ for each test is described in the legend of Figure 6). In the three-chamber test, CB1 mutation affected social interest in both sexes (interaction genotype $\mathrm{x}$ compartment: $\mathrm{F}_{2,20}=5.32$ and $\mathrm{F}_{2,22}=12.04, p<0.05$, respectively in males and females; Figure $6 \mathrm{a}-\mathrm{d}) . C B 1^{+/+}$and $C B 1^{+/-}$mice showed a clear preference for the compartment containing the social stimulus the (compartment effect: $\mathrm{F}_{1,7}=46.91$ and $\mathrm{F}_{1,9}=10.97, p<0.01$, respectively in $C B 1^{+/+}$and $C B 1^{+/-}$ males, and $\mathrm{F}_{1,11}=43.66$ and $\mathrm{F}_{1,6}=16.73, p<0.01$, respectively in $C B 1^{+/+}$and $C B 1^{+/-}$females), while social interest was absent in $\mathrm{CBI}^{-1-}$ adult males and females (compartment effect: $\mathrm{F}_{1,4}=0.49$ and $\mathrm{F}_{1,5}=3.09$, n.s., respectively in male and female mutants).

In the direct social interaction test, all mice displayed social habituation, as demonstrated by the reduced time spent in affiliation from the first to the last 5-min of the testing session (effect of 5-min bins, $\mathrm{F}_{1,19}=28.19, \mathrm{~F}_{1,22}=4.51, p<0.05$, respectively, in males and females; Figure 6b,e). CB1 mutation reduced social investigation, as demonstrated by the reduced time spent in affiliation by $C B 1^{-1-}$ males and females compared to their littermates (genotype effect, respectively: $\mathrm{F}_{2,19}=3.61$ and $\mathrm{F}_{2,22}=4.42, p<0.05$; post hoc: $p<0.05$; Figure 6b,e). In mice of both sexes, this effect was mainly due to a reduction in the time spent performing anogenital sniffing (Figure 6c-f); in males, this reduction was observed in both $C B 1^{+/-}$and $C B 1^{-1-}$ mice during the entire duration of the test (genotype effect: $\mathrm{F}_{2,19}=11.62, p<0.001$; post hoc: $p<0.05$; Figure 6c). In females, reduced anogenital sniffing was detected only in $C B 1^{-1-}$ mice and during the first $5 \mathrm{~min}$ of the test (genotype effect: $\mathrm{F}_{2,22}=4.45$, $p<0.05$; interaction genotype $\mathrm{x} 5$-min bin: $\mathrm{F}_{2,22}=$ $4.39, p<0.05$; post hoc: $p<0.05$; Figure 6f). No difference among experimental groups was found on nonsocial behaviors (data not shown).

\section{Experiment 3: Adult assessment of potentially confounding nonsocial alterations}

In the elevated plus maze, the $C B 1$ mutation in males or females did not results in behavioral differences either in the percent time spent in the open arms (all genotype effects, n.s.; Figure 7a,b), or in the total distance traveled (data not shown). Similarly, no differences between genotypes were detected in the auditory startle response in both sexes, with only an overall expected effect of pulse intensity $\left(\mathrm{F}_{3,72}=12.529, \mathrm{~F}_{3,93}=16.49, p<0.0001\right.$ in males and females, respectively; all genotype effects, n.s.; Figure $7 \mathrm{c}, \mathrm{d})$. 

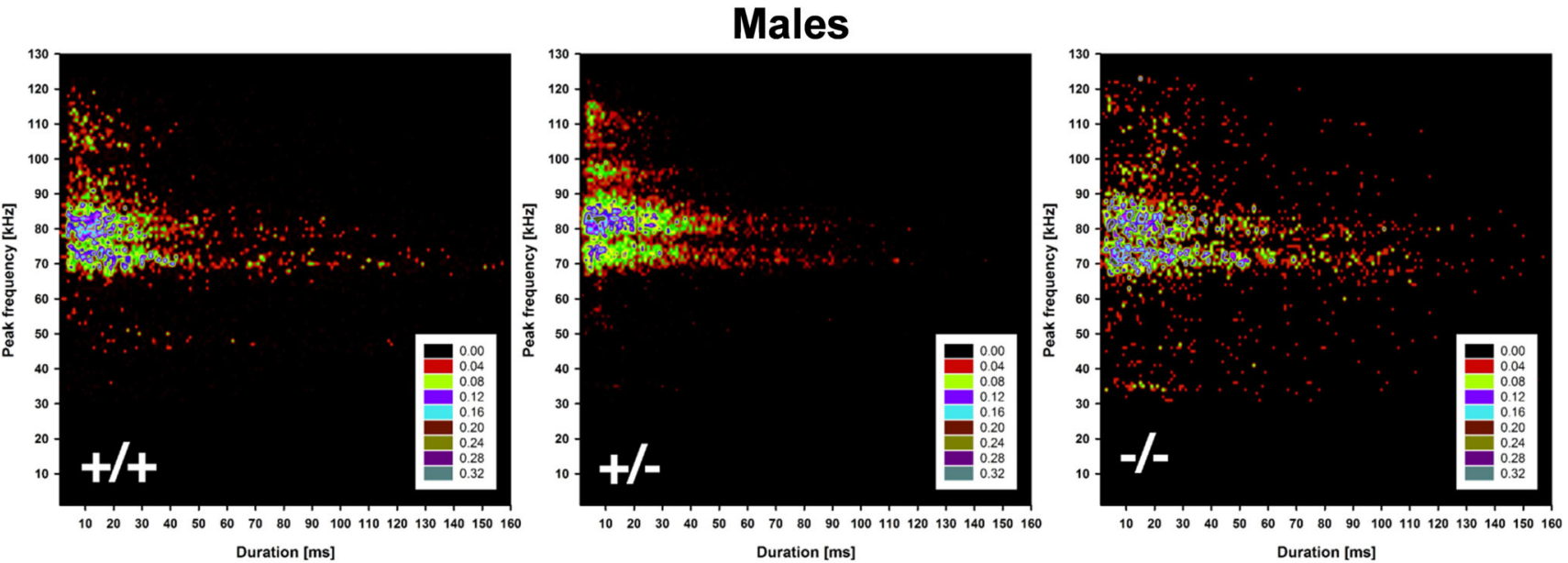

Females
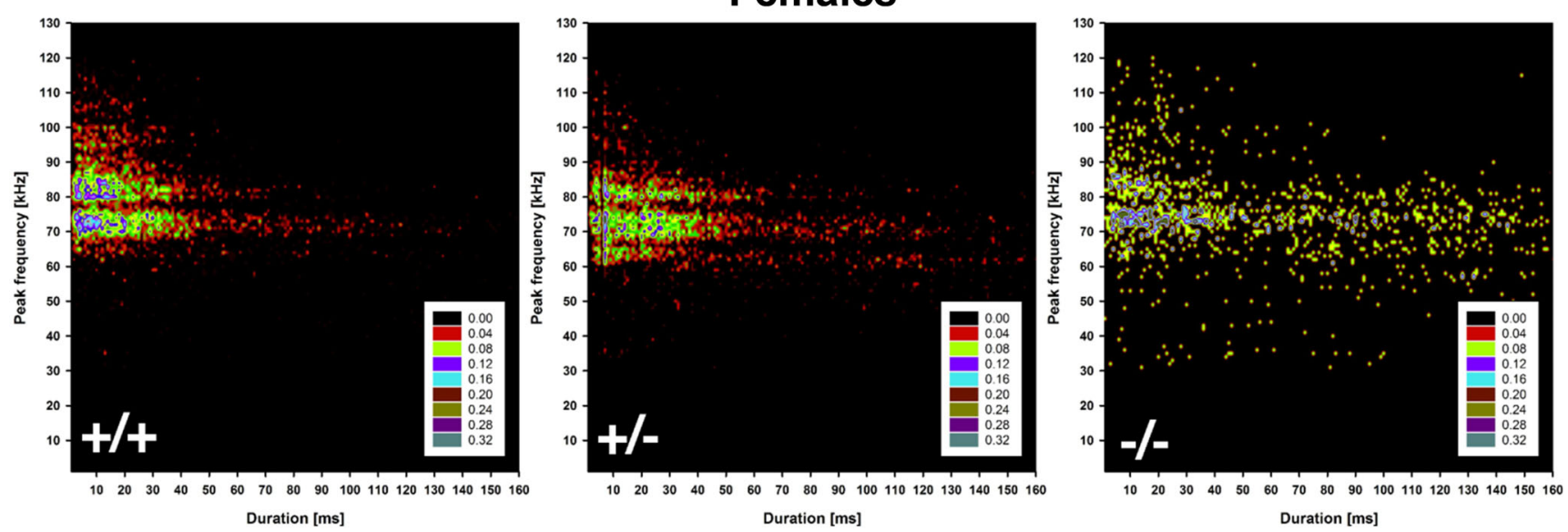

F I G U R E 5 Distribution of individual ultrasonic vocalizations (USV) in adult males and females. Density plots depict the distribution of individual USV emitted during 3-min social interaction with an intact NMRI adult female, plotted by frequency in $\mathrm{kHz}$ and duration in ms. Color coding reflects frequency in percentages

\section{DISCUSSION}

Our data demonstrate that the $C B 1$ mutation affects ultrasonic communication, both during development and at adulthood, as well as social interest/investigation at adult age. These ASD-relevant behavioral alterations were observed in both male and female mice, and overall seemed more marked in $C B 1^{-1-}$ than $C B 1^{+l-}$ mutants. Importantly, the adult USV alterations were not confounded by differences in anxiety or sensori-motor abilities, as assessed by the elevated plus maze and auditory startle tests. These findings add to previous evidence showing that $C B 1$ inhibition in mice induces repetitive and inflexible behaviors (Gomes et al., 2011; Pietropaolo et al., 2020; Terzian et al., 2011; Varvel \& Lichtman, 2002), that is, another core ASD-like symptom. Hence, our results further support the potential role of the ECS in the etiopathology of ASD and therefore its relevance as a therapeutic target for autistic pathologies. Our data also support the validity of the $C B I$ null mouse line not only for preclinical studies on ASD, but also for studies on the neurobiological mechanisms underlying the general control of social behaviors and communication.

The present study performed for the first time a comprehensive analysis of ultrasonic communication in $C B 1$ mutants during early postnatal development (between PND 4 and 10) and at adulthood (at 3 months of age). The alterations in USVs observed in $C B 1$ mutants were both quantitative and qualitative at both time points. During the postnatal period both male and female $C B 1^{-l-}$ pups showed altered day-dependent patterns of expression of multiple USV parameters. These patterns included a developmental profile (Branchi et al., 2001; Sungur et al., 2016) characterizing the number and mean duration of calls produced by $C B 1^{+/+}$mouse pups, with a peak around PND 4-6, followed by a reduction on PNDs 8 and 10 (Figure $2 \mathrm{a}-\mathrm{d}$ ). We observed here a slight divergence from the typical inverted-U shaped developmental USV patterns described in mouse pup studies (e.g., Branchi et al., 2001; Sungur et al., 2016) that could be due to the specific genetic background of our $C B 1$ mice, that is, the C57B16/N. B6/N mice differ from other 


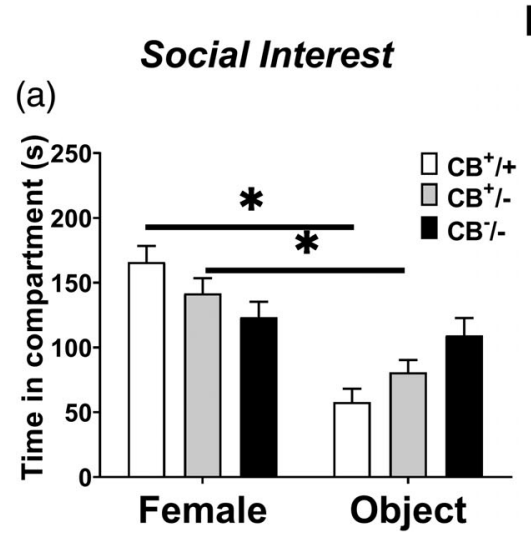

\section{Males}

(b)
Direct social interaction

(c)

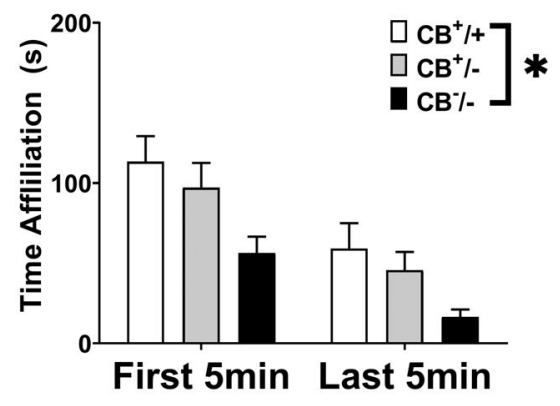

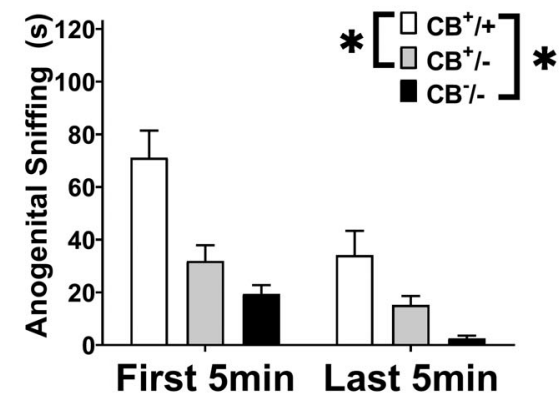

\section{Females}

\section{Social Interest}

(d)

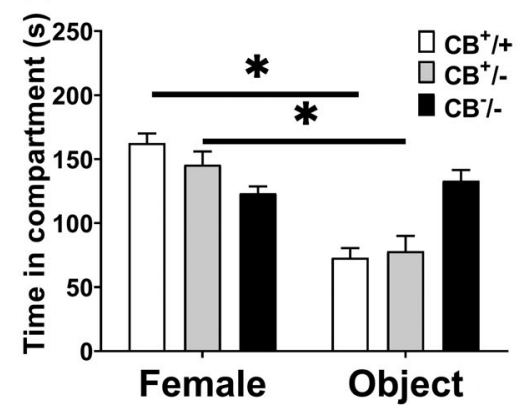

(e)

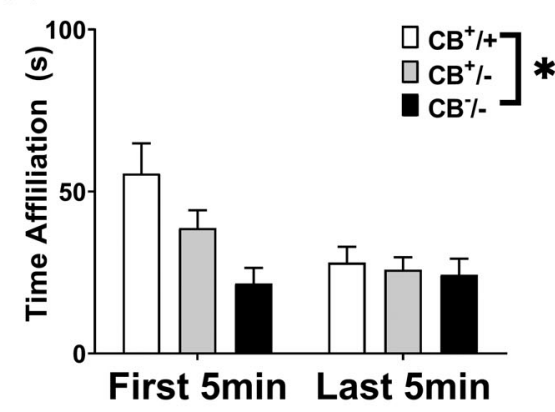

Direct social interaction

(f)

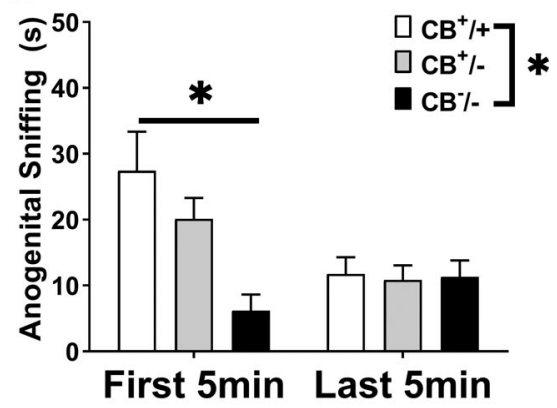

F I G U R E 6 Effects of the $C B 1$ null mutation on social interest and investigation in adult mice. Social interest (a,d) was assessed in the threechamber test. Social investigation was evaluated $48 \mathrm{~h}$ afterwards during a 10-min session of direct social interaction (b,c,e,f), based on the time spent performing affiliative behaviors (Gaudissard et al., 2017; Gauducheau et al., 2017; Oddi et al., 2015; Pietropaolo et al., 2014; Pietropaolo,

Guilleminot, et al., 2011), that is, sniffing the head and the snout of the partner, its anogenital region, or any other part of the body; contact with partner through traversing the partner's body by crawling over/under from one side to the other or allogrooming. Both tests used an unfamiliar ovariectomized NMRI stimulus female. The testing session was analyzed in 5-min bins in order to assess social habituation. ${ }^{*}=p<0.05$ (in $\mathrm{b}, \mathrm{c}, \mathrm{e}$, and $\mathrm{F}$, it refers to the main effect of genotype on the entire 10-min testing session). $\mathrm{N}$ (males) for both tests $=8\left(C B 1^{+/+}\right), 10\left(C B 1^{+/-}\right), 5\left(C B 1^{-/-}\right)$. $\mathrm{N}$ (females) for the three-chamber test $=12\left(C B 1^{+/+}\right), 7\left(C B 1^{+/-}\right), 6\left(C B 1^{-/-}\right) . \mathrm{N}$ (females) for the direct social interaction test $=11\left(C B 1^{+/+}\right)$, $8\left(C B 1^{+-}\right), 6\left(C B 1^{-l-}\right)$. Data are mean $\pm S E M$

B6 sub-strains in the number, peak amplitude and peak frequency of their USVs during infancy (Wohr et al., 2008), while at adulthood show slightly higher anxiety levels and reduced auditory startle than B6/J, without differing in their social behaviors (Matsuo et al., 2010).

While $C B 1^{-1-}$ pups demonstrated a similar peak in USV rate and duration, they did not show a comparable reduction on the following days. This finding suggests a delay in the development of communication abilities in $C B 1^{-1-}$ pups, a finding supported by the analysis of other parameters of pups' USVs. Indeed, USV mean peak frequencies also followed a clear developmental pattern, increasing from PNDs 4 to 10 (Figure 2e,f), but this linear increase was markedly reduced in $C B 1^{-1-}$ male and female pups. Furthermore, density plots revealed in $C B 1^{+/+}$pups the presence at PND 4 of a single cluster of lower mean peak frequency calls $(50-70 \mathrm{kHz})$, associated at PND 6 and 8 with a second cluster of higher frequency calls $(80-100 \mathrm{kHz})$, and disappearing on PND 10, when only the higher frequency cluster remained (Figure 3). In $C B 1^{+--}$and $C B 1^{-l-}$ pups both the high and low frequency clusters were instead still evident at PND 10; this finding resembles the pattern observed in the Shankl mouse model of ASD (Sungur et al., 2016), and further supports a delay in the communication abilities of $C B 1$ mutants.

The hypothesis of a general developmental delay in $C B 1$ mutants is further supported by their reduced body weight gain during the first 10 postnatal days (Figure 1); this reduced body growth was previously described in mouse pups following not only genetic (Fride et al., 2005), but also pharmacological inhibition of CB1r (Fride et al., 2001; Schechter et al., 2012), and it has been linked to reduced suckling and milk intake (Fride et al., 2001; Schechter et al., 2012). Nonetheless, body weight differences cannot directly explain the alterations in USV emission rates of $C B 1$ mutant pups, since they appear much earlier during postnatal development (i.e.,. at PND 4, while 
(a)
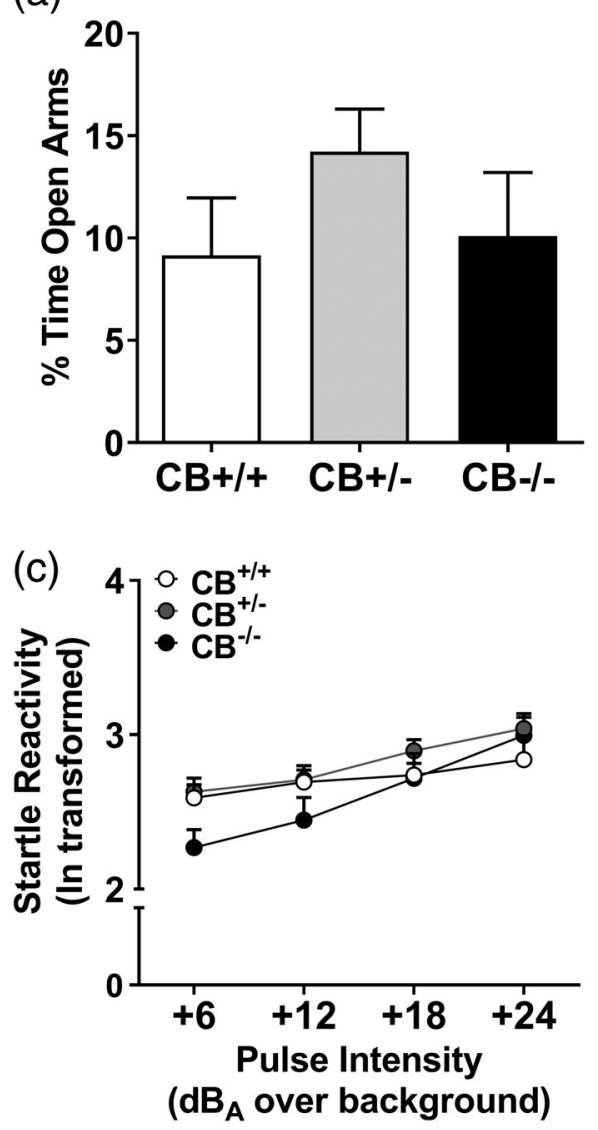

(b)

Females
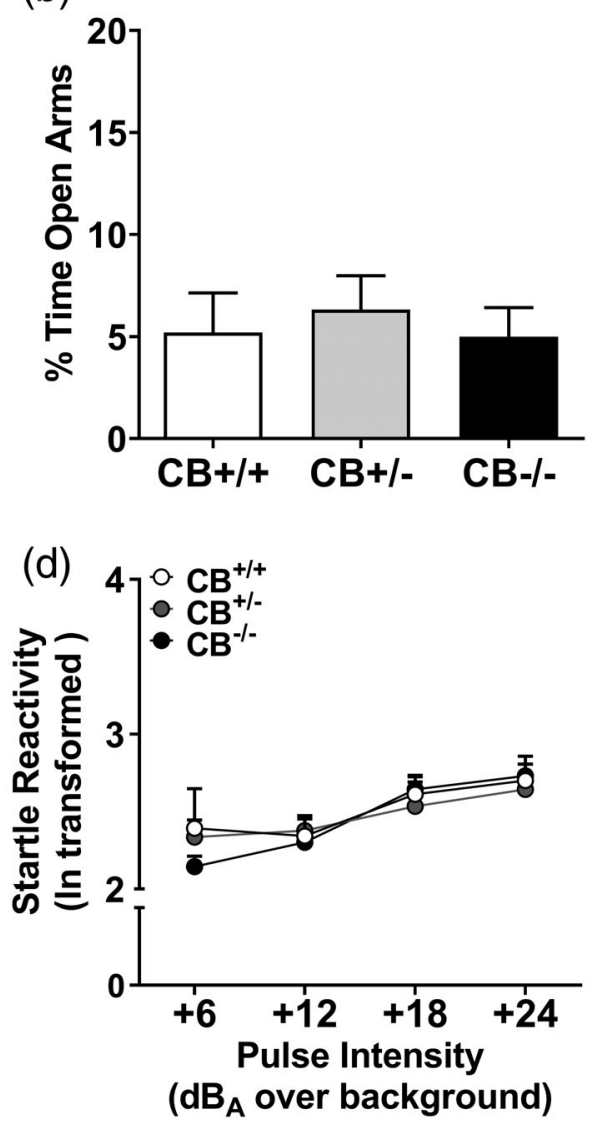

F I G U R E 7 Effects of the $C B 1$ null mutation on confounding nonsocial behaviors in adult mice. Anxiety-like behavior $(a, b)$ in the elevated plus maze and auditory startle response (c, d) were assessed in adult (3-months old) mice. $\mathrm{N}$ $($ males $)=9\left(\mathrm{CBI}^{+/+}\right), 16\left(\mathrm{CB1}^{+/-}\right)$, $9\left(C B 1^{-l-}\right) . \mathrm{N}($ females $)=7\left(C B 1^{+/+}\right)$, $9\left(\mathrm{CBI}^{+--}\right), 11\left(\mathrm{CBI}^{-l-}\right)$. Data are mean $\pm S E M$
USV alterations were first detected at PND 8). Furthermore, reductions in body weight are thought to lead to reduced emission rates of USVs because of the decreased pulmonary-thoracic size (Scattoni et al., 2008), while here an increase in USV number was observed on the last postnatal days (Figure 2a,b). Interestingly, an increase in USV rate was also previously described on PNDs 11-13 in rats following systemic administration of the $C B 1$ inverse agonist/antagonist rimonabant (McGregor et al., 1996). It is instead possible that an overall developmental delay in terms of reflexes and neuro-physiological development may be associated with the USV quantitative and qualitative alterations found in $C B 1$ mutant pups; future studies evaluating in depth developmental milestones (Branchi et al., 2004) are needed to investigate this issue that is, to our knowledge, still unknown in these mouse mutants.

Our findings on neonatal USVs point out to a developmental delay in $\mathrm{CB}^{-/-}$pups, since the day-dependent reduction of USV rate is supposed to correspond to increased pup maturity and reduced dependence from the mother (Caruso et al., 2020). Furthermore, previous studies have shown that USV rate in rodent pups reflect their affective state (Branchi et al., 2001; Zimmerberg et al., 1994), with an increase corresponding to an adverse emotional state (Caruso et al., 2020). An increase in pups' USV rate has been described in several mouse models of ASD [reviewed in (Caruso et al., 2020)] and it has been often interpreted as a sign of enhanced emotional distress; when accompanied by qualitative alterations in spectrographic parameters, such as mean duration or peak frequency, it has also been interpreted as a marker of altered communication abilities, within the context of mother-infant interactions. Interestingly, infants with ASD or at risk for developing ASD, when compared to typically developing infants, emit more cries with certain specific spectrographic characteristics (e.g., higher fundamental frequencies), that have been linked to more aversive conditions and negatively affect parental responses (Esposito et al., 2017; Esposito \& Venuti, 2010). Other studies have interpreted the enhanced rate of USVs described in mouse models of ASD as similar to the excessive talking and repetitive speech often found in autistic patients (e.g., Gauducheau et al., 2017, Wheeler et al., 2014). Interestingly, an enhanced mean duration of USVs was also described in the Fmr1-KO mouse model for ASD, both in pups (Gaudissard et al., 2017) and juveniles (Gauducheau et al., 2017), thus suggesting that longer calls may represent a consistent ASD-like phenotype, at least in young mice.

An alternative explanation for USV alterations in $C B 1$ pups may involve their altered response to stress, as USVs were assessed following a short maternal separation; several studies demonstrated an abnormal behavioral response of $C B 1$ null mice to stressors in general (Busquets-Garcia et al., 2016; Miller et al., 2008), often 
accompanied by enhanced neuro-endocrine reactivity (Barna et al., 2004). Furthermore, previous data demonstrated specifically an altered ultrasonic response to acute stress in $\mathrm{CB1}^{-/-}$mouse pups (Fride et al., 2005), similar to that previously described in rats following pharmacological CB1 modulation (Myose et al., 2019; Varga et al., 2012; Varga et al., 2017). Moreover, the persistence of USV alterations into adulthood in our $C B 1$ mutants strongly supports the presence of a genuine deficit in communication abilities in these mutants, which was indeed confirmed in the non-stressful context of direct social interaction with an adult female.

Male and female $\mathrm{CBI}^{-1-}$ mice showed in fact again at adulthood quantitative and qualitative USV alterations, including a reduction in the call rate (Figure $4 \mathrm{a}-\mathrm{e}$ ), and higher variations in the peak frequency and mean duration of the calls (i.e., reduced clustering), as revealed by the analysis of the density plots (Figure 5). The reduced USV rate is in line with what is observed in other ASD mouse models (Silverman et al., 2010), for example, the BTBR (McFarlane et al., 2008; Scattoni et al., 2011), Shank (Ey et al., 2011; Schmeisser et al., 2012) or Fmrl-KO mouse lines (Rotschafer et al., 2012), thus supporting the relevance of this quantitative USV alteration as an ASD-like phenotype.

Interestingly, the USV alterations of $C B 1$ mutants were not accompanied by altered anxiety or reduced startle response, as found in other mouse models for ASD (Pietropaolo \& Subashi, 2014; Yang et al., 2015). In fact here $C B 1$ mutants did not differ from their WT littermates in the elevated plus maze and auditory startle tests (Figure 7), in line with previous studies showing that behaviors in these tests were not consistently and robustly affected by CBI homozygous deletion (Haller et al., 2002; Haller et al., 2004; Marongiu et al., 2012). While the USV alterations observed in $C B 1$ male and female mutants at adulthood were not linked to emotional or sensori-motor abnormalities, they were instead associated with deficits in social interest in the threechamber test and in social investigation (Figure 6); interestingly, the genotype differences were more marked for anogenital sniffing, a behavior that has been shown to positively correlate with USVs rate in adult mice (Moles et al., 2007; Nyby, 1983). This finding, together with the presence of social and USV alterations in both sexes, suggests that $C B 1$ mutation may affect social interactions and communication by acting on the general sociability of mice. It is possible that other confounding factors may influence the genotype effects observed here on adult social behaviors, such as deficits in olfactory abilities, as well as general reduced explorative behavior and altered locomotor activity. Nonetheless, these behavioral confounders were ruled out by previous studies describing no abnormalities in olfactory discrimination tests (Hutch et al., 2015), and inconsistent alterations in object exploration and locomotion (e.g., Dubreucq et al., 2010; Haller et al., 2002; Haring et al., 2011; Lafenetre et al., 2009).
Our data from the total distance moved in the elevated plus maze and nonsocial exploration in the direct social interaction test further support the lack of confounding differences in locomotion/exploration between WT and CB1 mutants.

The deficits showed in social interest and behavior in adult $C B 1$ mutants are in agreement with previous reports on $C B 1^{-1-}$ male mice (Haller et al., 2004; Haring et al., 2011; Litvin et al., 2013; Terzian et al., 2014), even with stimuli of different sex (Haller et al., 2004; Haring et al., 2011; Litvin et al., 2013; Terzian et al., 2014) and genetic background (Terzian et al., 2014), thus confirming these as a robust behavioral phenotype of $C B 1$ null mice. Reduced social investigation and social interest in $\mathrm{CB} 1^{-/-}$male mice was previously described toward an ovariectomised female in hormonally-induced estrous phase (Terzian et al., 2014), thus suggesting the limited impact of the estrous phase of the female stimulus on the social deficit of CB1 mutants. Also, similar deficits in USV rate and social investigation (again, especially on anogenital sniffing) were observed following pharmacological $C B 1$ inhibition by rimonabant in male mice, in a dose-dependent manner (Pietropaolo et al., 2020). In agreement with our results, stimulating the endocannabinoid tone by the administration of anandamide hydrolysis inhibitor URB597 induced an increase in social investigation, as well as in the emission rate of USVs (although mostly those at $50 \mathrm{kHz}$ ) in adult rats (Manduca et al., 2014). To our knowledge, this is the first time that USV and social alterations are described also in $C B 1^{+/-}$mice, also including female subjects; here, females seem more sensitive to the early effects of $C B 1$ mutation, since during development $C B 1^{+/-}$females (but not males) differed in body weight and USVs from WT littermates similarly to $C B 1^{-1-}$. At adulthood, "a dosage" effect of $C B 1$ mutation seemed evident in males and females, with one allele somehow protecting from the effects of $C B 1$ deletion, and $\mathrm{CB1} 1^{+/-}$positioning between $\mathrm{CBI}^{-/-}$and $\mathrm{CB1^{+/+ }}$. Despite a traditional focus on the male sex, ASD-research is indeed increasingly interested in evaluating pathological behavioral phenotypes also in females subjects, as ASD female patients may have unique clinical presentations relative to their male counterparts, a factor that may have led to under diagnosis of ASD in the female sex (Loomes et al., 2017). Hence, the presence of communication and social phenotypes in $C B 1$ mutant females add to the value of the $C B 1$ null mouse to study ASD, an issue that is receiving increasing attention in preclinical research on this pathology (e.g., studies in female Fmrl-KO mice modeling ASD, (Gauducheau et al., 2017).

In conclusion, our data support the use of the $C B 1$ null mouse in preclinical research on ASD. The lack of nonsocial alterations, that is, emotional or sensori-motor abnormalities, does not undermine the validity of $C B 1$ mutants to study ASD, although they may be considered ASD-like phenotypes; first, because recapitulating the 
full ASD-like phenotypes is increasingly considered an unrealistic and unnecessary goal of mouse models (Crawley, 2004, 2007; Moy et al., 2006; Silverman et al., 2010), second because it allows to rule out important confounds potentially acting on social and communication behaviors. Thus, the $C B 1$ null mouse may be instrumental in specifically investigating the neurobiology of social behaviors and communication, that is, the core ASD symptoms, without including other nonsocial symptoms. This approach is particularly suitable to the $C B 1$ null model, because of the availability of mutant $C B 1$ mouse lines with region- and cell-specific deletions (Bellocchio et al., 2010; Busquets-Garcia et al., 2016; Hebert-Chatelain et al., 2014; Marsicano \& Lutz, 1999; Oliveira da Cruz et al., 2016; Robin et al., 2018), allowing dissecting the behavioral role of $C B 1$ according to its expression site (e.g., glutamatergic, gabaergic, dopaminergic neurons, in the whole cell or mitochondria only). Hence, future studies combining region-and cell-specific deletions of $C B 1$ will be able to identify the structures and circuits responsible for the social and communication deficits, thus providing novel avenues for research on ASD.

\section{ACKNOWLEDGMENTS}

This work was supported by CNRS and the Universite de Bordeaux; William Fyke was the recipient of a fellowship provided by SUNY Downstate Medical Center (MD-PhD Program). Marika Premoli was funded by an institutional grant from the Università degli Studi di Brescia and CIB ("Consorzio Interuniversitario per le Biotecnologie"). José López-Moreno and Victor Echeverry Alzate are supported by a grant from the National Plan on Drug abuse, Ministerio de Sanidad of Spain (PNSD2018-050 to José A. LópezMoreno), and the Fondo de Investigación Sanitaria (Red de Trastornos Adictivos, FEDER, RD16/0017/0008 to José A. López-Moreno). Victor Echeverry Alzate holds a "Sara Borrell" research contract (CD17/00125) funded by the Instituto de Salud Carlos III. The funders had no role in study design, data collection and analysis, decision to publish, or preparation of the manuscript.

\section{CONFLICT OF INTEREST}

The authors have no conflict of interest to report in relation to the work described.

\section{ORCID}

William Fyke (1) https://orcid.org/0000-0001-8389-9899 Susanna Pietropaolo (1) https://orcid.org/0000-0002-89931922

\section{REFERENCES}

Assaf, M., Jagannathan, K., Calhoun, V. D., Miller, L., Stevens, M. C., Sahl, R., O'Boyle, J. G., Schultz, R. T., \& Pearlson, G. D. (2010) Abnormal functional connectivity of default mode sub-networks in autism spectrum disorder patients. NeuroImage, 53(1), 247-256. https://doi.org/10.1016/j.neuroimage.2010.05.067

Association, A. P. (2013). Diagnostic and statistical manual of mental disorders (DSM- $5^{\circledR}$ ).
Bar-Lev Schleider, L., Mechoulam, R., Saban, N., Meiri, G., \& Novack, V. (2019). Real life experience of medical cannabis treatment in autism: Analysis of safety and efficacy. Scientific Reports, 9(1), 1-7. https://doi.org/10.1038/s41598-018-37570-y

Barna, I., Zelena, D., Arszovszki, A. C., \& Ledent, C. (2004). The role of endogenous cannabinoids in the hypothalamo-pituitary-adrenal axis regulation: In vivo and in vitro studies in CB1 receptor knockout mice. Life Sciences, 75(24), 2959-2970. https://doi.org/10.1016/ j.lfs.2004.06.006

Baudoin, C., Feron, C., \& Magnusson, M. S. (1991). Male-female interactions in staggerer and non-mutant mice: Impairment to react to novelty as a possible explanation of staggerer male social behaviour. Behavioural Processes, 24(1), 49-58. https://doi.org/10.1016/ 0376-6357(91)90086-F

Belagodu, A. P., Johnson, A. M., \& Galvez, R. (2016). Characterization of ultrasonic vocalizations of fragile X mice. Behavioural Brain Research, 310, 76-83. https://doi.org/10.1016/j.bbr.2016.04.016

Bellocchio, L., Lafenêtre, P., Cannich, A., Cota, D., Puente, N., Grandes, P., Chaouloff, F., Piazza, P. V., \& Marsicano, G. (2010). Bimodal control of stimulated food intake by the endocannabinoid system. Nature Neuroscience, 13(3), 281-283. https://doi.org/10.1038/nn.2494

Berghuis, P., Rajnicek, A. M., Morozov, Y. M., Ross, R. A., Mulder, J., Urban, G. M., Monory, K., Marsicano, G., Matteoli, M., Canty, A., Irving, A. J., Katona, I., Yanagawa, Y., Rakic, P., Lutz, B., Mackie, K., \& Harkany, T. (2007). Hardwiring the brain: Endocannabinoids shape neuronal connectivity. Science, 316(5828), 1212-1216.

Branchi, I., Santucci, D., \& Alleva, E. (2001). Ultrasonic vocalisation emitted by infant rodents: A tool for assessment of neurobehavioural development. Behavioural Brain Research, 125 (1-2), 49-56.

Branchi, I., Santucci, D., Puopolo, M., \& Alleva, E. (2004). Neonatal behaviors associated with ultrasonic vocalizations in mice (Mus musculus): A slow-motion analysis. Developmental Psychobiology, 44(1), 37-44.

Brudzynski, S. M. (2009). Handbook of mammalian vocalization: An integrative neuroscience approach (Vol. 19). Academic Press.

Busquets-Garcia, A., Gomis-González, M., Srivastava, R. K., Cutando, L., Ortega-Alvaro, A., Ruehle, S., Remmers, F., Bindila, L., Bellocchio, L., Marsicano, G., Lutz, B., Maldonado, R., \& Ozaita, A. (2016). Peripheral and central CB1 cannabinoid receptors control stress-induced impairment of memory consolidation. Proceedings of the National Academy of Sciences of the United States of America, 113(35), 9904-9909. https:// doi.org/10.1073/pnas.1525066113

Caligioni, C. S. (2009). Assessing reproductive status/stages in mice. Current Protocols in Neuroscience, 48, Appendix 4-Appendix 4I. https://doi.org/10.1002/0471142301.nsa04is48

Caruso, A., Ricceri, L., \& Scattoni, M. L. (2020). Ultrasonic vocalizations as a fundamental tool for early and adult behavioral phenotyping of autism Spectrum disorder rodent models. Neuroscience and Biobehavioral Reviews, 116, 31-43. https://doi.org/10. 1016/j.neubiorev.2020.06.011

Charan, J., \& Kantharia, N. D. (2013). How to calculate sample size in animal studies? Journal of Pharmacology and Pharmacotherapeutics, 4(4), 303-306. https://doi.org/10.4103/0976-500x.119726

Chiarotti, F., Alleva, E., \& Bignami, G. (1987). Problems of test choice and data analysis in behavioral teratology: The case of prenatal benzodiazepines. Neurotoxicology and Teratology, 9(2), 179-186. https://doi.org/10.1016/0892-0362(87)90096-1

Crawley, J. N. (2004). Designing mouse behavioral tasks relevant to autistic-like behaviors. Mental Retardation and Developmental Disabilities Research Reviews, 10(4), 248-258.

Crawley, J. N. (2007). Mouse behavioral assays relevant to the symptoms of autism. Brain Pathology, 17(4), 448-459.

Crusio, W. E. (1996). Gene-targeting studies: New methods, old problems. Trends in Neurosciences, 19(5), 186-187 discussion 188-189. 
Crusio, W. E., Goldowitz, D., Holmes, A., \& Wolfer, D. (2009). Standards for the publication of mouse mutant studies. Genes, Brain and Behavior, 8(1), 1-4.

De Rubeis, S., \& Buxbaum, J. D. (2015). Genetics and genomics of autism spectrum disorder: Embracing complexity. Human Molecular Genetics, 24(R1), R24-R31. https://doi.org/10.1093/hmg/ $\operatorname{ddv} 273$

Devane, W. A., Hanus, L., Breuer, A., Pertwee, R. G., Stevenson, L. A., Griffin, G., Gibson, D., Mandelbaum, A., Etinger, A., \& Mechoulam, R. (1992). Isolation and structure of a brain constituent that binds to the cannabinoid receptor. Science, 258(5090), 1946-1949.

Diaz-Alonso, J., Aguado, T., Wu, C. S., Palazuelos, J., Hofmann, C., Garcez, P., Guillemot, F., Lu, H. C., Lutz, B., Guzman, M., \& Galve-Roperh, I. (2012). The CB(1) cannabinoid receptor drives corticospinal motor neuron differentiation through the Ctip2/Satb2 transcriptional regulation axis. The Journal of Neuroscience, 32(47), 16651-16665. https://doi.org/10.1523/ JNEUROSCI.0681-12.2012

Dubreucq, S., Koehl, M., Abrous, D. N., Marsicano, G., \& Chaouloff, F. (2010). CB1 receptor deficiency decreases wheelrunning activity: Consequences on emotional behaviours and hippocampal neurogenesis. Experimental Neurology, 224(1), 106-113. https://doi.org/10.1016/j.expneurol.2010.01.017

Esposito, G., Hiroi, N., \& Scattoni, M. L. (2017). Cry, baby, cry: Expression of distress as a biomarker and modulator in autism Spectrum disorder. The International Journal of Neuropsychopharmacology, 20 (6), 498-503. https://doi.org/10.1093/ijnp/pyx014

Esposito, G., \& Venuti, P. (2010). Understanding early communication signals in autism: A study of the perception of infants' cry. Journal of Intellectual Disability Research, 54(3), 216-223. https://doi.org/ 10.1111/j.1365-2788.2010.01252.x

Ey, E., Leblond, C. S., \& Bourgeron, T. (2011). Behavioral profiles of mouse models for autism spectrum disorders. Autism Research, 4 , $5-16$.

Festing, M. F., \& Altman, D. G. (2002). Guidelines for the design and statistical analysis of experiments using laboratory animals. ILAR Journal, 43(4), 244-258. https://doi.org/10.1093/ilar.43. 4.244

Fish, E. W., Faccidomo, S., Gupta, S., \& Miczek, K. A. (2004). Anxiolytic-like effects of escitalopram, citalopram, and R-citalopram in maternally separated mouse pups. The Journal of Pharmacology and Experimental Therapeutics, 308(2), 474-480. https://doi.org/10. 1124/jpet.103.058206

Folstein, S., \& Rutter, M. (1977). Infantile autism: A genetic study of 21 twin pairs. Journal of Child Psychology and Psychiatry, 18(4), 297-321.

Francia, N., Simeoni, M., Petruzzi, S., Santucci, D., Aloe, L., \& Alleva, E. (2006). Repeated acute exposures to hypergravity during early development subtly affect CD-1 mouse neurobehavioural profile. Brain Research Bulletin, 69(5), 560-572. https://doi.org/10. 1016/j.brainresbull.2006.02.019

Fride, E., Ginzburg, Y., Breuer, A., Bisogno, T., Di Marzo, V., \& Mechoulam, R. (2001). Critical role of the endogenous cannabinoid system in mouse pup suckling and growth. European Journal of Pharmacology, 419(2-3), 207-214. https://doi.org/10.1016/ s0014-2999(01)00953-0

Fride, E., Suris, R., Weidenfeld, J., \& Mechoulam, R. (2005). Differential response to acute and repeated stress in cannabinoid $\mathrm{CB} 1$ receptor knockout newborn and adult mice. Behavioural Pharmacology, 16(5-6), 431-440.

Gaudissard, J., Ginger, M., Premoli, M., Memo, M., Frick, A., \& Pietropaolo, S. (2017). Behavioral abnormalities in the Fmr1-KO2 mouse model of fragile $\mathrm{X}$ syndrome: The relevance of early life phases. Autism Research, 10(10), 1584-1596. https://doi.org/10. 1002/aur.1814

Gauducheau, M., Lemaire-Mayo, V., D'Amato, F. R., Oddi, D., Crusio, W. E., \& Pietropaolo, S. (2017). Age-specific autistic-like behaviors in heterozygous Fmr1-KO female mice. Autism Research, 10(6), 1067-1078. https://doi.org/10.1002/aur.1743

Gomes, F. V., Casarotto, P. C., Resstel, L. B., \& Guimaraes, F. S. (2011). Facilitation of CB1 receptor-mediated neurotransmission decreases marble burying behavior in mice. Progress in NeuroPsychopharmacology \& Biological Psychiatry, 35(2), 434-438. https://doi.org/10.1016/j.pnpbp.2010.11.027

Haller, J., Bakos, N., Szirmay, M., Ledent, C., \& Freund, T. F. (2002). The effects of genetic and pharmacological blockade of the CB1 cannabinoid receptor on anxiety. The European Journal of Neuroscience, 16(7), 1395-1398.

Haller, J., Varga, B., Ledent, C., Barna, I., \& Freund, T. F. (2004). Context-dependent effects of CB1 cannabinoid gene disruption on anxiety-like and social behaviour in mice. The European Journal of Neuroscience, 19(7), 1906-1912. https://doi.org/10.1111/j.14609568.2004.03293.x

Hammerschmidt, K., Radyushkin, K., Ehrenreich, H., \& Fischer, J. (2009). Female mice respond to male ultrasonic 'songs' with approach behaviour. Biology Letters, 5(5), 589-592. https://doi. org/10.1098/rsbl.2009.0317

Hanson, J. L., \& Hurley, L. M. (2012). Female presence and estrous state influence mouse ultrasonic courtship vocalizations. PLoS One, 7(7), e40782. https://doi.org/10.1371/journal.pone.0040782

Haring, M., Kaiser, N., Monory, K., \& Lutz, B. (2011). Circuit specific functions of cannabinoid CB1 receptor in the balance of investigatory drive and exploration. PLoS One, 6(11), e26617. https://doi. org/10.1371/journal.pone.0026617

Harris, S. W., Hessl, D., Goodlin-Jones, B., Ferranti, J., Bacalman, S., Barbato, I., Tassone, F., Hagerman, P. J., Herman, K., \& Hagerman, R. J. (2008). Autism profiles of males with fragile X syndrome. American Journal of Mental Retardation, 113(6), 427438. https://doi.org/10.1352/2008.113:427-438

Hébert, B., Pietropaolo, S., Même, S., Laudier, B., Laugeray, A., Doisne, N., Quartier, A., Lefeuvre, S., Got, L., Cahard, D., Laumonnier, F., Crusio, W. E., Pichon, J., Menuet, A., Perche, O., \& Briault, S. (2014). Rescue of fragile X syndrome phenotypes in Fmr1 KO mice by a BKCa channel opener molecule. Orphanet Journal of Rare Diseases, 9, 124.

Hebert-Chatelain, E., Reguero, L., Puente, N., Lutz, B., Chaouloff, F., Rossignol, R., Piazza, P. V., Benard, G., Grandes, P., \& Marsicano, G. (2014). Studying mitochondrial CB1 receptors: Yes we can. Molecular Metabolism, 3(4), 339. https://doi.org/10.1016/j. molmet.2014.03.008

Hutch, C. R., Hillard, C. J., Jia, C., \& Hegg, C. C. (2015). An endocannabinoid system is present in the mouse olfactory epithelium but does not modulate olfaction. Neuroscience, 300, 539-553. https://doi.org/10.1016/j.neuroscience.2015.05.056

Jimenez, J. A., \& Zylka, M. J. (2021). Controlling litter effects to enhance rigor and reproducibility with rodent models of neurodevelopmental disorders. Journal of Neurodevelopmental Disorders, 13(1), 2. https://doi.org/10.1186/s11689-020-09353-y

Jung, K. M., Sepers, M., Henstridge, C. M., Lassalle, O., Neuhofer, D., Martin, H., Ginger, M., Frick, A., DiPatrizio, N. V., Mackie, K., Katona, I., Piomelli, D., \& Manzoni, O. J. (2012). Uncoupling of the endocannabinoid signalling complex in a mouse model of fragile X syndrome. Nature Communications, 3, 1080.

Karhson, D. S., Krasinska, K. M., Dallaire, J. A., Libove, R. A., Phillips, J. M., Chien, A. S., Garner, J. P., Hardan, A. Y., \& Parker, K. J. (2018). Plasma anandamide concentrations are lower in children with autism spectrum disorder. Molecular Autism, 9, 18. https://doi.org/10.1186/s13229-018-0203-y

Keown, C. L., Datko, M. C., Chen, C. P., Maximo, J. O., Jahedi, A., \& Muller, R. A. (2017). Network organization is globally atypical in autism: A graph theory study of intrinsic functional connectivity. Biological Psychiatry: Cognitive Neuroscience and Neuroimaging, 2 (1), 66-75. https://doi.org/10.1016/j.bpsc.2016.07.008

Kim, H., Son, J., Yoo, H., Kim, H., Oh, J., Han, D., Hwang, Y., \& Kaang, B. K. (2016). Effects of the female estrous cycle on the 
sexual behaviors and ultrasonic vocalizations of male C57BL/6 and autistic BTBR $\mathrm{T}+\mathrm{tf} / \mathrm{J}$ mice. Experimental Neurobiology, 25 (4), 156-162. https://doi.org/10.5607/en.2016.25.4.156

Lafenetre, P., Chaouloff, F., \& Marsicano, G. (2009). Bidirectional regulation of novelty-induced behavioral inhibition by the endocannabinoid system. Neuropharmacology, 57(7-8), 715-721. https://doi.org/10.1016/j.neuropharm.2009.07.014

Litvin, Y., Phan, A., Hill, M. N., Pfaff, D. W., \& McEwen, B. S. (2013). CB1 receptor signaling regulates social anxiety and memory. Genes, Brain, and Behavior, 12(5), 479-489. https://doi.org/10. 1111/gbb. 12045

Liu, P. Y., Erkkila, K., Lue, Y., Jentsch, J. D., Schwarcz, M. D., Abuyounes, D., Hikim, A. S., Wang, C., Lee, P. W. N., \& Swerdloff, R. S. (2010). Genetic, hormonal, and metabolomic influences on social behavior and sex preference of XXY mice. American Journal of Physiology. Endocrinology and Metabolism, 299(3), E446-E455. https://doi.org/10.1152/ajpendo.00085.2010

Loomes, R., Hull, L., \& Mandy, W. P. L. (2017). What is the male-tofemale ratio in autism Spectrum disorder? A systematic review and meta-analysis. Journal of the American Academy of Child and Adolescent Psychiatry, 56(6), 466-474. https://doi.org/10.1016/j.jaac. 2017.03.013

Mackie, K. (2005). Distribution of cannabinoid receptors in the central and peripheral nervous system. Handbook of Experimental Pharmacology, 168, 299-325.

Maggio, J. C., \& Whitney, G. (1985). Ultrasonic vocalizing by adult female mice (Mus musculus). Journal of Comparative Psychology, 99(4), 420-436.

Manduca, A., Servadio, M., Campolongo, P., Palmery, M., Trabace, L., Vanderschuren, L. J., Cuomo, V., \& Trezza, V. (2014). Strain- and context-dependent effects of the anandamide hydrolysis inhibitor URB597 on social behavior in rats. European Neuropsychopharmacology, 24(8), 1337-1348. https://doi.org/10. 1016/j.euroneuro.2014.05.009

Marongiu, M. F., Poddie, D., Porcu, S., Manchinu, M. F., Castelli, M. P., Sogos, V., Bini, V., Frau, R., Caredda, E., Collu, M., \& Ristaldi, M. S. (2012). Reversible disruption of prepulse inhibition in hypomorphic-inducible and reversible CB1-/mice. PLoS One, 7(4), e35013. https://doi.org/10.1371/journal. pone. 0035013

Marsicano, G., \& Lutz, B. (1999). Expression of the cannabinoid receptor $\mathrm{CB} 1$ in distinct neuronal subpopulations in the adult mouse forebrain. European Journal of Neuroscience, 11(12), 4213-4225.

Marsicano, G., Wotjak, C. T., Azad, S. C., Bisogno, T., Rammes, G., Cascio, M. G., Lutz, B., Tang, J., Hofmann, C., Zieglgänsberger, W., di Marzo, V., \& Lutz, B. (2002). The endogenous cannabinoid system controls extinction of aversive memories. Nature, 418(6897), 530-534.

Matsuo, N., Takao, K., Nakanishi, K., Yamasaki, N., Tanda, K., \& Miyakawa, T. (2010). Behavioral profiles of three C57BL/6 substrains. Frontiers in Behavioral Neuroscience, 4, 29. https://doi.org/ 10.3389/fnbeh.2010.00029

McFarlane, H. G., Kusek, G. K., Yang, M., Phoenix, J. L., Bolivar, V. J., \& Crawley, J. N. (2008). Autism-like behavioral phenotypes in BTBR $\mathrm{T}+\mathrm{tf} / \mathrm{J}$ mice. Genes, Brain, and Behavior, 7 (2), 152-163.

McGregor, I. S., Dastur, F. N., McLellan, R. A., \& Brown, R. E. (1996). Cannabinoid modulation of rat pup ultrasonic vocalizations. European Journal of Pharmacology, 313(1-2), 43-49.

Miller, L. L., Ward, S. J., \& Dykstra, L. A. (2008). Chronic unpredictable stress enhances cocaine-conditioned place preference in type 1 cannabinoid receptor knockout mice. Behavioural Pharmacology, 19(5-6), 575-581. https://doi.org/10.1097/FBP. 0b013e32830ded 11

Moles, A., Costantini, F., Garbugino, L., Zanettini, C., \& D'Amato, F. R. (2007). Ultrasonic vocalizations emitted during dyadic interactions in female mice: A possible index of sociability? Behavioural Brain Research, 182(2), 223-230.
Moles, A., \& D'Amato, F. R. (2000). Ultrasonic vocalization by female mice in the presence of a conspecific carrying food cues. Animal Behaviour, 60(5), 689-694.

Mosienko, V., Beis, D., Alenina, N., \& Wohr, M. (2015). Reduced isolation-induced pup ultrasonic communication in mouse pups lacking brain serotonin. Molecular Autism, 6, 13. https://doi.org/ 10.1186/s13229-015-0003-6

Moy, S. S., Nadler, J. J., Magnuson, T. R., \& Crawley, J. N. (2006). Mouse models of autism spectrum disorders: The challenge for behavioral genetics. American Journal of Medical Genetics. Part C, Seminars in Medical Genetics, $142 C(1), 40-51$.

Mulder, J., Aguado, T., Keimpema, E., Barabas, K., Ballester Rosado, C. J., Nguyen, L., Monory, K., Marsicano, G., di Marzo, V., Hurd, Y. L., Guillemot, F., Mackie, K., Lutz, B., Guzman, M., Lu, H. C., Galve-Roperh, I., \& Harkany, T. (2008). Endocannabinoid signaling controls pyramidal cell specification and long-range axon patterning. Proceedings of the National Academy of Sciences of the United States of America, 105(25), 87608765. https://doi.org/10.1073/pnas.0803545105

Myose, T., Shirakawa, A., Irie, K., Yamashita, Y., Nakano, T., Takase, Y., Matsuo, K., Satho, T., Tuchihashi, R., Kinjo, J., Tanaka, H., Morimoto, S., Funada, M., Sano, K., \& Mishima, K. (2019). Delta(9)-Tetrahydrocannabinol elicited 22-kHz ultrasonic vocalization changes after air puff stimulus through $\mathrm{CB} 1$ receptor in adult rats. Neuroscience Letters, 701, 132-135. https://doi.org/ 10.1016/j.neulet.2019.02.010

Nadler, J. J., Moy, S. S., Dold, G., Simmons, N., Perez, A., Young, N. B., Barbaro, R. P., Piven, J., Magnuson, T. R., \& Crawley, J. N. (2004). Automated apparatus for quantitation of social approach behaviors in mice. Genes, Brain, and Behavior, 3 (5), 303-314.

Nair, A., Treiber, J. M., Shukla, D. K., Shih, P., \& Muller, R. A. (2013). Impaired thalamocortical connectivity in autism spectrum disorder: A study of functional and anatomical connectivity. Brain, 136(Pt 6), 1942-1955. https://doi.org/10.1093/brain/awt079

Nyby, J. (1983). Ultrasonic vocalizations during sex behavior of male house mice (Mus musculus): A description. Behavioral and Neural Biology, 39(1), 128-134.

Nyby, J., Wysocki, C. J., Whitney, G., Dizinno, G., \& Schneider, J. (1979). Elicitation of male mouse (Mus musculus) ultrasonic vocalizations: I. urinary cues. Journal of Comparative and Physiological Psychology, 93(5), 967-976.

Oddi, D., Subashi, E., Middei, S., Bellocchio, L., Lemaire-Mayo, V., Guzmán, M., Crusio, W. E., D’Amato, F. R., \& Pietropaolo, S. (2015). Early social enrichment rescues adult behavioral and brain abnormalities in a mouse model of fragile $\mathrm{X}$ syndrome. Neuropsychopharmacology, 40(5), 1113-1122. https://doi.org/10. 1038/npp.2014.291

Oliveira da Cruz, J. F., Robin, L. M., Drago, F., Marsicano, G., \& Metna-Laurent, M. (2016). Astroglial type-1 cannabinoid receptor (CB1): A new player in the tripartite synapse. Neuroscience, 323, 35-42. https://doi.org/10.1016/j.neuroscience.2015.05.002

Pardo, C. A., \& Eberhart, C. G. (2007). The neurobiology of autism. Brain Pathology, 17(4), 434- 447.

Pietropaolo, S., Bellocchio, L., Bouzon-Arnaiz, I., \& Yee, B. K. (2020). The role of the endocannabinoid system in autism spectrum disorders: Evidence from mouse studies. Progress in Molecular Biology and Translational Science, 173, 183-208. https://doi.org/10.1016/ bs.pmbts.2020.04.016

Pietropaolo, S., Bellocchio, L., Ruiz-Calvo, A., Cabanas, M., du, Z., Guzmán, M., Garret, M., \& Cho, Y. H. (2015). Chronic cannabinoid receptor stimulation selectively prevents motor impairments in a mouse model of Huntington's disease. Neuropharmacology, 89, 368-374. https://doi.org/10.1016/j. neuropharm.2014.07.021

Pietropaolo, S., \& Crusio, W. E. (2009). Strain-dependent changes in acoustic startle response and its plasticity across adolescence in mice. Behavior Genetics, 39, 623-631. 
Pietropaolo, S., Delage, P., Cayzac, S., Crusio, W. E., \& Cho, Y. H. (2011). Sex-dependent changes in social behaviors in motor presymptomatic R6/1 mice. PLoS One, 6(5), e19965.

Pietropaolo, S., Delage, P., Lebreton, F., Crusio, W. E., \& Cho, Y. H. (2012). Early development of social deficits in APP and APP-PS1 mice. Neurobiology of Aging, 33(5), 1002-1027. https://doi.org/10. 1016/j.neurobiolaging.2011.09.012

Pietropaolo, S., Goubran, M. G., Joffre, C., Aubert, A., LemaireMayo, V., Crusio, W. E., \& Laye, S. (2014). Dietary supplementation of omega-3 fatty acids rescues fragile $\mathrm{X}$ phenotypes in Fmr1-Ko mice. Psychoneuroendocrinology, 49, 119-129. https:// doi.org/10.1016/j.psyneuen.2014.07.002

Pietropaolo, S., Guilleminot, A., Martin, B., D’Amato, F. R., \& Crusio, W. E. (2011). Genetic-background modulation of core and variable autistic-like symptoms in FMR1 knock-out mice. PLoS One, 6(2), e17073.

Pietropaolo, S., \& Subashi, E. (2014). Mouse models of fragile X syndrome. In S. Pietropaolo, F. Sluyter, \& W. E. Crusio (Eds.), Behavioral genetics of the mouse (Vol. 2, pp. 146-163). Cambridge University Press.

Pretzsch, C. M., Freyberg, J., Voinescu, B., Lythgoe, D., Horder, J., Mendez, M. A., Wichers, R., Ajram, L., Ivin, G., Heasman, M., Edden, R. A. E., Williams, S., Murphy, D. G. M., Daly, E., \& McAlonan, G. M. (2019). Effects of cannabidiol on brain excitation and inhibition systems; a randomised placebo-controlled single dose trial during magnetic resonance spectroscopy in adults with and without autism spectrum disorder. Neuropsychopharmacology, 44, 1398-1405. https://doi.org/10.1038/ s41386-019-0333-8

Ricceri, L., Moles, A., \& Crawley, J. (2007). Behavioral phenotyping of mouse models of neurodevelopmental disorders: Relevant social behavior patterns across the life span. Behavioural Brain Research, 176(1), 40-52.

Robin, L. M., Oliveira da Cruz, J. F., Langlais, V. C., MartinFernandez, M., Metna-Laurent, M., Busquets-Garcia, A., Bellocchio, L., Soria-Gomez, E., Papouin, T., Varilh, M., Sherwood, M. W., Belluomo, I., Balcells, G., Matias, I., Bosier, B., Drago, F., van Eeckhaut, A., Smolders, I., Georges, F., ... Marsicano, G. (2018). Astroglial CB1 receptors determine synaptic D-serine availability to enable recognition memory. Neuron, 98(5), 935-944.e5 e935. https://doi.org/10.1016/j.neuron.2018. 04.034

Rotschafer, S. E., Trujillo, M. S., Dansie, L. E., Ethell, I. M., \& Razak, K. A. (2012). Minocycline treatment reverses ultrasonic vocalization production deficit in a mouse model of fragile $\mathrm{X}$ syndrome. Brain Research, 1439, 7-14.

Scattoni, M. L., Crawley, J., \& Ricceri, L. (2009). Ultrasonic vocalizations: A tool for behavioural phenotyping of mouse models of neurodevelopmental disorders. Neuroscience and Biobehavioral Reviews, 33(4), 508-515.

Scattoni, M. L., Gandhy, S. U., Ricceri, L., \& Crawley, J. N. (2008). Unusual repertoire of vocalizations in the BTBR $\mathrm{T}+\mathrm{tf} / \mathrm{J}$ mouse model of autism. PLoS One, 3(8), e3067.

Scattoni, M. L., Ricceri, L., \& Crawley, J. N. (2011). Unusual repertoire of vocalizations in adult BTBR $\mathrm{T}+\mathrm{tf} / \mathrm{J}$ mice during three types of social encounters. Genes, Brain, and Behavior, 10(1), 44-56.

Schechter, M., Pinhasov, A., Weller, A., \& Fride, E. (2012). Blocking the postpartum mouse dam's CB1 receptors impairs maternal behavior as well as offspring development and their adult socialemotional behavior. Behavioural Brain Research, 226(2), 481-492. https://doi.org/10.1016/j.bbr.2011.10.016

Schmeisser, M. J., Ey, E., Wegener, S., Bockmann, J., Stempel, A. V., Kuebler, A., Janssen, A. L., Udvardi, P. T., Shiban, E., Spilker, C., Balschun, D., Skryabin, B. V., Dieck, S., Smalla, K. H., Montag, D., Leblond, C. S., Faure, P., Torquet, N., le Sourd, A. M., ... Boeckers, T. M. (2012). Autisticlike behaviours and hyperactivity in mice lacking
ProSAP1/Shank2. Nature, 486(7402), 256-260. https://doi.org/10. 1038/nature11015

Sebat, J., Lakshmi, B., Malhotra, D., Troge, J., Lese-Martin, C., Walsh, T., Yamrom, B., Yoon, S., Krasnitz, A., Kendall, J., Leotta, A., Pai, D., Zhang, R., Lee, Y. H., Hicks, J., Spence, S. J., Lee, A. T., Puura, K., Lehtimaki, T., ... Wigler, M. (2007). Strong association of de novo copy number mutations with autism. Science, 316(5823), 445-449.

Shah, C. R., Forsberg, C. G., Kang, J. Q., \& Veenstra-VanderWeele, J. (2013). Letting a typical mouse judge whether mouse social interactions are atypical. Autism Research, 6(3), 212-220. https://doi. org/10.1002/aur.1280

Shonesy, B. C., Parrish, W. P., Haddad, H. K., Stephenson, J. R., Báldi, R., Bluett, R. J., Marks, C. R., Centanni, S. W., Folkes, O. M., Spiess, K., Augustin, S. M., Mackie, K., Lovinger, D. M., Winder, D. G., Patel, S., \& Colbran, R. J. (2018). Role of striatal direct pathway 2-Arachidonoylglycerol signaling in sociability and repetitive behavior. Biological Psychiatry, 84(4), 304-315. https://doi.org/10.1016/j.biopsych.2017.11.036

Shubrata, K. S., Sinha, S., Seshadri, S. P., Girimaji, S., Subbakrishna, D. K., \& Srinath, S. (2015). Childhood autism spectrum disorders with and without epilepsy: Clinical implications. Journal of Child Neurology, 30(4), 476-482. https://doi.org/10. $1177 / 0883073814540521$

Silverman, J. L., \& Crawley, J. N. (2014). The promising trajectory of autism therapeutics discovery. Drug Discovery Today, 19(7), 838844. https://doi.org/10.1016/j.drudis.2013.12.007

Silverman, J. L., Yang, M., Lord, C., \& Crawley, J. N. (2010). Behavioural phenotyping assays for mouse models of autism. Nature Reviews. Neuroscience, 11(7), 490-502.

Simola, N., \& Granon, S. (2019). Ultrasonic vocalizations as a tool in studying emotional states in rodent models of social behavior and brain disease. Neuropharmacology, 159, 107420. https://doi.org/10. 1016/j.neuropharm.2018.11.008

Smith, D. R., Stanley, C. M., Foss, T., Boles, R. G., \& McKernan, K. (2017). Rare genetic variants in the endocannabinoid system genes CNR1 and DAGLA are associated with neurological phenotypes in humans. PLoS One, 12(11), e0187926. https://doi.org/10.1371/ journal.pone. 0187926

Spencer, C. M., Alekseyenko, O., Hamilton, S. M., Thomas, A. M., Serysheva, E., Yuva-Paylor, L. A., \& Paylor, R. (2011). Modifying behavioral phenotypes in Fmr1KO mice: Genetic background differences reveal autistic-like responses. Autism Research, 4(1), $40-56$.

Still, A. W. (1982). On the number of subjects used in animal behavior experiments. Animal Behaviour, 30, 873-880. https://doi.org/10. 1016/S0003-3472(82)80161-9

Sugiura, T., Kondo, S., Sukagawa, A., Nakane, S., Shinoda, A., Itoh, K., Yamashita, A., \& Waku, K. (1995). 2-Arachidonoylgylcerol: A possible endogenous cannabinoid receptor ligand in brain. Biochemical and Biophysical Research Communications, 215(1), 89-97.

Sungur, A. O., Schwarting, R. K., \& Wohr, M. (2016). Early communication deficits in the Shank1 knockout mouse model for autism spectrum disorder: Developmental aspects and effects of social context. Autism Research, 9(6), 696-709. https://doi.org/10.1002/ aur. 1564

Terzian, A. L., Drago, F., Wotjak, C. T., \& Micale, V. (2011). The dopamine and cannabinoid interaction in the modulation of emotions and cognition: Assessing the role of cannabinoid CB1 receptor in neurons expressing dopamine D1 receptors. Frontiers in Behavioral Neuroscience, 5, 49. https://doi.org/10.3389/fnbeh.2011. 00049

Terzian, A. L., Micale, V., \& Wotjak, C. T. (2014). Cannabinoid receptor type 1 receptors on GABAergic vs. glutamatergic neurons differentially gate sex-dependent social interest in mice. The European Journal of Neuroscience, 40(1), 2293-2298. https://doi. org/10.1111/ejn.12561 
Varga, B., Kassai, F., \& Gyertyan, I. (2012). Interactions of CB1 and mGlu5 receptor antagonists in food intake, anxiety and memory models in rats. Pharmacology, Biochemistry, and Behavior, 103(2), 425-430. https://doi.org/10.1016/j.pbb.2012.09.016

Varga, B., Kassai, F., Szabo, G., Kovacs, P., Fischer, J., \& Gyertyan, I. (2017). Pharmacological comparison of traditional and nontraditional cannabinoid receptor 1 blockers in rodent models in vivo. Pharmacology, Biochemistry, and Behavior, 159, 24-35. https://doi.org/10.1016/j.pbb.2017.06.012

Varvel, S. A., \& Lichtman, A. H. (2002). Evaluation of CB1 receptor knockout mice in the Morris water maze. The Journal of Pharmacology and Experimental Therapeutics, 301(3), 915-924. https:// doi.org/10.1124/jpet.301.3.915

Velinov, M. (2019). Genomic copy number variations in the autism clinic-Work in Progress. Frontiers in Cellular Neuroscience, 13 (57), 1-6. https://doi.org/10.3389/fncel.2019.00057

Veronesi, V. B., Batista, T. H., Ribeiro, A. C., Giusti-Paiva, A., \& Vilela, F. C. (2017). Maternal dipyrone treatment during lactation in mice reduces maternal behavior and increases anxiety-like behavior in offspring. International Journal of Developmental Neuroscience, 58, 74-81. https://doi.org/10.1016/j.ijdevneu.2017. 02.005

Vivian, J. A., \& Miczek, K. A. (1993). Diazepam and gepirone selectively attenuate either $20-32$ or $32-64 \mathrm{kHz}$ ultrasonic vocalizations during aggressive encounters. Psychopharmacology, 112(1), 66-73. https://doi.org/10.1007/BF02247364

Wada, H. (2017). Acoustic alterations of ultrasonic vocalization in rat pups induced by perinatal hypothyroidism. Neurotoxicology, 59, 175-182. https://doi.org/10.1016/j.neuro.2016.05.017

Wang, H., Liang, S., Burgdorf, J., Wess, J., \& Yeomans, J. (2008). Ultrasonic vocalizations induced by sex and amphetamine in M2, M4, M5 muscarinic and D2 dopamine receptor knockout mice. PLoS One, 3(4), e1893.

Warburton, V. L., Sales, G. D., \& Milligan, S. R. (1989). The emission and elicitation of mouse ultrasonic vocalizations: The effects of age, sex and gonadal status. Physiology \& Behavior, 45(1), 41-47.

Webber, E. S., Mankin, D. E., McGraw, J. J., Beckwith, T. J., \& Cromwell, H. C. (2013). Ultrasonic vocalizations, predictability and sensorimotor gating in the rat. Behavioural Brain Research, 253, 32-41. https://doi.org/10.1016/j.bbr.2013.07.013

Wheeler, A., Raspa, M., Bann, C., Bishop, E., Hessl, D., Sacco, P., \& Bailey, D. B. (2014). Anxiety, attention problems, hyperactivity, and the Aberrant Behavior Checklist in fragile X syndrome. American Journal of Medical Genetics Part A, 164(1), 141-155. https:// doi.org/10.1002/ajmg.a.36232

White, N. R., Prasad, M., Barfield, R. J., \& Nyby, J. G. (1998). 40-and $70-\mathrm{kHz}$ vocalizations of mice (Mus musculus) during copulation. Physiology \& Behavior, 63(4), 467-473.

Whitney, G., Coble, J. R., Stockton, M. D., \& Tilson, E. F. (1973). Ultrasonic emissions: Do they facilitate courtship of mice. Journal of Comparative and Physiological Psychology, 84(3), 445-452.

Wohr, M. (2014). Ultrasonic vocalizations in shank mouse models for autism spectrum disorders: Detailed spectrographic analyses and developmental profiles. Neuroscience and Biobehavioral Reviews, 43, 199-212. https://doi.org/10.1016/j.neubiorev.2014.03.021

Wohr, M., Dahlhoff, M., Wolf, E., Holsboer, F., Schwarting, R. K., \& Wotjak, C. T. (2008). Effects of genetic background, gender, and early environmental factors on isolation-induced ultrasonic calling in mouse pups: An embryo-transfer study. Behavior Genetics, 38 (6), 579-595. https://doi.org/10.1007/s10519-008-9221-4

Wöhr, M., Orduz, D., Gregory, P., Moreno, H., Khan, U., Vörckel, K. J., Wolfer, D. P., Welzl, H., Gall, D., Schiffmann, S. N., \&
Schwaller, B. (2015). Lack of parvalbumin in mice leads to behavioral deficits relevant to all human autism core symptoms and related neural morphofunctional abnormalities. Translational Psychiatry, 5, e525. https://doi.org/10.1038/tp.2015.19

Wohr, M., Roullet, F. I., Hung, A. Y., Sheng, M., \& Crawley, J. N. (2011). Communication impairments in mice lacking Shank1: Reduced levels of ultrasonic vocalizations and scent marking behavior. PLoS One, 6 (6), e20631. https://doi.org/10.1371/journal.pone.0020631

Wohr, M., \& Scattoni, M. L. (2013). Behavioural methods used in rodent models of autism spectrum disorders: Current standards and new developments. Behavioural Brain Research, 251, 5-17. https://doi.org/10.1016/j.bbr.2013.05.047

Wohr, M., Silverman, J. L., Scattoni, M. L., Turner, S. M., Harris, M. J., Saxena, R., \& Crawley, J. N. (2013). Developmental delays and reduced pup ultrasonic vocalizations but normal sociability in mice lacking the postsynaptic cell adhesion protein neuroligin2. Behavioural Brain Research, 251, 50-64. https://doi.org/ 10.1016/j.bbr.2012.07.024

Yang, M., Bozdagi, O., Scattoni, M. L., Wohr, M., Roullet, F. I., Katz, A. M., Abrams, D. N., Kalikhman, D., Simon, H., Woldeyohannes, L., Zhang, J. Y., Harris, M. J., Saxena, R., Silverman, J. L., Buxbaum, J. D., \& Crawley, J. N. (2012). Reduced excitatory neurotransmission and mild autism-relevant phenotypes in adolescent Shank3 null mutant mice. The Journal of Neuroscience, 32 (19), 6525-6541. https://doi.org/10.1523/JNEUROSCI.6107-11.2012

Yang, M., Mahrt, E. J., Lewis, F., Foley, G., Portmann, T., Dolmetsch, R. E., Portfors, C. V., \& Crawley, J. N. (2015). 16 p11.2 deletion syndrome mice display sensory and ultrasonic vocalization deficits during social interactions. Autism Research, 8 (5), 507-521. https://doi.org/10.1002/aur.1465

Zamberletti, E., Gabaglio, M., \& Parolaro, D. (2017). The Endocannabinoid system and autism Spectrum disorders: Insights from animal models. International Journal of Molecular Sciences, 18(9), 1-14. https://doi.org/10.3390/ijms18091916

Zhang, Y., Bonnan, A., Bony, G., Ferezou, I., Pietropaolo, S., Ginger, M., Sans, N., Rossier, J., Oostra, B., LeMasson, G., \& Frick, A. (2014). Dendritic channelopathies contribute to neocortical and sensory hyperexcitability in Fmr1(-/y) mice. Nature Neuroscience, 17(12), 1701-1709. https://doi.org/10.1038/nn.3864

Zimmerberg, B., Brunelli, S. A., \& Hofer, M. A. (1994). Reduction of rat pup ultrasonic vocalizations by the neuroactive steroid allopregnanolone. Pharmacology, Biochemistry, and Behavior, 47(3), 735-738. https://doi.org/10.1016/0091-3057(94)90181-3

Zorrilla, E. P. (1997). Multiparous species present problems (and possibilities) to developmentalists. Developmental Psychobiology, 30(2), 141-150. https://doi.org/10.1002/(sici)1098-2302(199703)30:2<141:: aid-dev5>3.0.co;2-q

How to cite this article: Fyke, W., Premoli, M., Echeverry Alzate, V., López-Moreno, J. A., Lemaire-Mayo, V., Crusio, W. E., Marsicano, G., Wöhr, M., \& Pietropaolo, S. (2021). Communication and social interaction in the cannabinoid-type 1 receptor null mouse: Implications for autism spectrum disorder. Autism Research, 14(9), 1854-1872. https://doi.org/10. 1002/aur.2562 